Board of Governors of the Federal Reserve System

International Finance Discussion Papers

Number 795

April 2004

PRICE-LEVEL DETERMINACY, LOWER BOUNDS ON THE
NOMINAL INTEREST RATE, AND LIQUIDITY TRAPS

Ragna Alstadheim and Dale W. Henderson

NOTE: International Finance Discussion Papers are preliminary materials circulated to stimulate discussion and critical comment. References to International Finance Discussion Papers (other than an acknowledgment that the writer has had access to unpublished material) should be cleared with the author or authors. Recent IFDPs are available on the Web at www.federalreserve.gov/pubs/ifdp. 


\title{
PRICE-LEVEL DETERMINACY, LOWER BOUNDS ON THE NOMINAL INTEREST RATE, AND LIQUIDITY TRAPS
}

\author{
Ragna Alstadheim and Dale W. Henderson*
}

\begin{abstract}
We consider monetary-policy rules with inflation-rate targets and interest-rate or money-growth instruments using a flexible-price, perfect-foresight model. There is always a locally-unique target equilibrium. There may also be below-target equilibria (BTE) with inflation always below target and constant, asymptotically approaching or eventually reaching a below-target value, or oscillating. Liquidity traps are neither necessary nor sufficient for BTE which can arise if monetary policy keeps the interest rate above a lower bound. We construct monetary rules that preclude BTE when fiscal policy does not. Plausible fiscal policies preclude BTE for any monetary policy; those policies exclude surpluses and, possibly, balanced budgets.
\end{abstract}

Keywords: price-level indeterminacy, multiple equilibria, zero bound, liquidity trap, monetary policy, monetary rule, fiscal policy, money demand

*Alstadheim is an Assistant Professor at Howard University, and Henderson is a Special Adviser in the Division of International Finance at the Federal Reserve Board. For helpful comments, we thank David Bowman, Matthew Canzoneri, Behzad Diba, Refet Gurkaynak, Berthold Herrendorf, Lars Svensson, and participants in a session at the 2001 meetings of the Southern Economics Association; in seminars at Georgetown University, the Federal Reserve Board, and the European Central Bank; and in the Konstanz Seminar on Monetary Theory and Monetary Policy. Remaining errors are our own. Alstadheim thanks the Center for Monetary and Financial Research in Norway and the Federal Reserve Board for financial support and hospitality. The views in this paper are solely the responsibility of the authors and should not be interpreted as reflecting those of the Board of Governors of the Federal Reserve System or any other person associated with the Federal Reserve System. The email addresses of the authors are, respectively, ra7@georgetown.edu and dale.henderson@,frb.gov. 


\section{Introduction and summary}

In this paper we discuss price-level determinacy when there is a lower bound on the (nominal) interest rate. The lower bound may arise either because of the behavior of (private) agents or because of monetary policy. For generality and relevance, our analysis is conducted in terms of the inflation rate instead of the price level. ${ }^{1}$ In our terminology, a model exhibits (inflation-rate) indeterminacy if it has multiple equilibria.

Determinacy in flexible-price models is of both theoretical and practical interest. As regards theory, inflation-rate determinacy is a standard topic. Furthermore, in models with synchronized price contracts, agents must be able to determine what expected inflation would be under price flexibility in order to set their contract prices. As regards practice, the current situation in Japan, with deflation and zero shortterm interest rates, makes it more urgent to ascertain whether the possible existence of multiple equilibria is more than a theoretical curiosum.

Recently, the possibility of indeterminacy has received much attention. Models with standard interest-rate rules or money-growth rules and a locally unique steadystate target equilibrium $(T E)$ for the inflation rate may have additional equilibria. To be more precise, there may be multiple below-target equilibria (BTE), paths along which the inflation rate is always below target and is constant or either asymptotically approaches or eventually reaches a below-target value. ${ }^{2}$ Fiscal policy may preclude $B T E$; in particular, a balanced-budget fiscal policy precludes $B T E$ in which the interest rate is always at a zero lower bound. ${ }^{3}$

We illustrate, modify, and extend recent analysis using a perfect-foresight, superneutral model with flexible prices which may have a liquidity trap. We adopt what we regard as the conventional definition of a liquidity trap: a liquidity trap is a region of the money-demand function in which bonds and money are perfect substitutes so that open-market operations in bonds cannot lower the interest rate any further. ${ }^{4}$ In our model, a liquidity trap may arise at a zero or at a strictly positive interest rate.

\footnotetext{
${ }^{1}$ Of course, inflation-rate determinacy and price-level determinacy are linked. If the inflation rate (defined as the percentage change in the price level between today and yesterday) is determined and yesterday's price level is known, then today's price level is determined.

${ }^{2}$ A 1999 version of Woodford (2003) cited by Benhabib, Schmitt-Grohe, and Uribe (2001a) contains an explanation of the possible existence of BTE with both interest-rate rules and money-supply rules. In Woodford (2003) and Benhabib, Schmitt-Grohe, and Uribe (2001b) the inflation rate may asymptotically approach a below-target steady state; in Schmitt-Grohe and Uribe (2000), Benhabib, Schmitt-Grohe, and Uribe (2001a) and Eggertson and Woodford (2003) it may eventually reach a below-target steady state.

${ }^{3}$ Woodford (2001a) and Benhabib, Schmitt-Grohe, and Uribe (2001a) consider fiscal policy. Schmitt-Grohe and Uribe (2000) analyze balanced-budget fiscal policy.

${ }^{4} \mathrm{McCallum}$ (2001) refers to a 'liquidity trap situation' as a situation in which 'the (usual) interest rate instrument is immobilized'. Svensson (2000) refers to a liquidity trap as a situation with a binding zero lower bound on the nominal interest rate. Krugman (1998) refers to a liquidity trap as a situation where "monetary policy loses its grip because the nominal interest rate is essentially
} 
It is useful to summarize what we do. We present accessible derivations of the central results regarding indeterminacy given the existence of a lower bound on the interest rate. ${ }^{5}$ We distinguish clearly between a lower bound that arises because of monetary policy and one that arises because agents are in a liquidity trap. It turns out that a liquidity trap is neither necessary nor sufficient for BTE.

We also consider monetary-policy rules that preclude BTE. The monetary policy rules used in deriving indeterminacy results are monotonic in the inflation rate. We present two kinds of monetary-policy rules that may preclude BTE. First, elaborating on an observation in Benhabib, Schmitt-Grohe, and Uribe (2001b), we demonstrate that monetary-policy rules that are not monotonic in the inflation rate may preclude $B T E$. Second, we present a rule under which the interest rate responds to expected future inflation as well as to current inflation. This rule is asymmetric: the interest rate responds more strongly to expected future inflation if the current inflation rate is below the target rate.

In addition, we show how conclusions about determinacy under alternative monetary rules depend on fiscal policy. For simplicity, we characterize fiscal policy by the growth rate of total nominal government debt. ${ }^{6}$ There is always a growth rate of debt high enough to preclude BTE no matter what the monetary policy because BTE paths would violate the transversality condition. A balanced-budget fiscal policy (a zero growth rate of debt) is not expansionary enough if the interest rate is positive at least part of the time either because of a positive lower bound or, for example, because of foreseen variation in productivity. Within a range, the combination of a small deficit with a standard interest-rate or money-supply rule guarantees that the $T E$ is the unique equilibrium because the deficit precludes $B T E$.

In the next section we lay our model and discuss two specific money-demand functions. Section 3 is a presentation of some results regarding the existence of BTE with interest-rate rules. We discuss indeterminacy under money-growth rules in section 4. In section 5, we present monetary-policy rules that assure determinacy. Section 6 is a discussion of some implications of fiscal policy for determinacy. Concluding remarks are provided in section 7 .

zero [and] the quantity of money becomes irrelevant because money and bonds are essentially perfect substitutes'. Our definition is the same as Krugman's except that, like Sargent (1987) among others, we explicitly allow for a liquidity trap at a positive interest rate.

${ }^{5}$ Since our model has flexible prices and exhibits superneutrality, a lower bound can give rise to only nominal indeterminacy. However, using a model with sticky prices, Benhabib, Schmitt-Grohe, and Uribe (2001b) show that a lower bound can give rise not only to nominal indeterminacy but also to real indeterminacy.

${ }^{6}$ The characterization of fiscal policy in Eggertson and Woodford (2003) is more general and includes ours as a special case. 


\section{The model}

\subsection{Agents}

Our model economy is populated by a continuum of agents each of which acts simultaneously as a consumer and a producer. For simplicity, we assume that the product market is perfectly competitive, that prices are flexible, and that agents have perfect foresight. The problem of each agent is to find the

$$
\begin{gathered}
\underset{C_{t}, B_{t}, M_{t}, Y_{t}}{\operatorname{Max}} \sum_{t=0}^{\infty} \beta^{t}\left\{U\left(C_{t}\right)+V\left(m_{t}\right)-\left[1 /\left(2 \rho_{t}\right)\right] Y_{t}^{2}\right\} \\
U^{\prime}\left(C_{t}\right)>0, \quad U^{\prime \prime}\left(C_{t}\right)<0, \quad m_{t}=M_{t} / P_{t}, \quad V^{\prime}\left(m_{t}\right) \geq 0, \quad V^{\prime \prime}\left(m_{t}\right) \leq 0
\end{gathered}
$$

subject to the following period budget and positivity constraints:

$$
\begin{gathered}
P_{t} Y_{t}+M_{t-1}+I_{t-1} B_{t-1}=T_{t}+P_{t} C_{t}+M_{t}+B_{t} \\
C_{t}>0, M_{t}>0, P_{t}>0, \rho_{t}>0 \quad \forall t
\end{gathered}
$$

Period utility is increasing in consumption, weakly increasing in real (money) balances $m_{t}$, and decreasing in output. ${ }^{7} \rho_{t}$ represents the level of productivity; as $\rho_{t}$ increases the production of a given level of output causes less disutility. ${ }^{8}$ The agent takes as given the money price of goods $\left(P_{t}\right)$ and the gross nominal interest rate $\left(I_{t}\right)$ earned on a bond held from period $t$ to period $t+1$, and chooses holdings of two nominal financial assets, money $\left(M_{t}\right)$ and bonds $\left(B_{t}\right)$; consumption $\left(C_{t}\right)$; and output $\left(Y_{t}\right)$. According to the period budget constraint, nominal income from production in this period plus nominal money balances and bond holdings inclusive of interest from last period must equal tax payments $T_{t}$ plus the sum of consumption and money and bond holdings for this period. In addition, each agent and, therefore, agents as a group are subject to a no-Ponzi-game condition:

$$
\lim _{t \rightarrow \infty}\left(M_{t}+B_{t}\right) \prod_{k=0}^{k=t-1} I_{k}^{-1} \geq 0, \quad \prod_{k=0}^{k=-1} I_{k}^{-1} \equiv 1
$$

where $M_{t}+B_{t}$ is their net (nominal) financial assets in period $t$.

\footnotetext{
${ }^{7}$ We consider specific functional forms for $V\left(m_{t}\right)$ in section 2.3 and for $U\left(C_{t}\right)$ in section 6.3.

${ }^{8}$ Increases in $\rho_{t}$ can be interpreted either as increases in productivity or decreases in the disutility of labor if agents supply their desired amounts of labor either because they are consumer-producers or because they participate in a labor market that clears. Following Obstfeld and Rogoff (1996), let $-\phi_{t} l_{t}$ be the disutility associated with labor $\left(l_{t}\right)$ and let $A_{t} l_{t}^{\frac{1}{2}}$ be the production function. Inverting the production function yields

$$
-\phi_{t} l_{t}=-\phi_{t}\left(y_{t} / A_{t}\right)^{2}=-\left[1 /\left(2 \rho_{t}\right)\right] y_{t}^{2}, \quad \rho_{t}=A_{t}^{2} /\left(2 \phi_{t}\right)
$$
}


To simplify exposition, in sections 2 - 6 we express the nominal interest rate, the real interest rate and inflation rate in gross terms and refer to them as 'the interest rate', 'the real interest rate', and 'the inflation rate' respectively. In the introductory and concluding sections, we refer to the net nominal interest rate as 'the interest rate' in order to facilitate comparison of our results to those of others.

Three necessary conditions for an optimum are

$$
\begin{array}{ll}
U^{\prime}\left(C_{t}\right)=\beta U^{\prime}\left(C_{t+1}\right) \frac{I_{t}}{\Pi_{t+1}} & \text { (bonds) } \\
U^{\prime}\left(C_{t}\right)=V^{\prime}\left(m_{t}\right)+\beta U^{\prime}\left(C_{t+1}\right) \frac{1}{\Pi_{t+1}} & \text { (money) } \\
C_{t}=\rho_{t} U^{\prime}\left(C_{t}\right) & \text { (output) }
\end{array}
$$

where $\Pi_{t+1}=\frac{P_{t+1}}{P_{t}}$ is the (backward looking) gross inflation rate. A fourth necessary condition (the transversality condition) is that (3) hold with equality

$$
\lim _{t \rightarrow \infty}\left(M_{t}+B_{t}\right) \Pi_{k=0}^{k=t-1} I_{k}^{-1}=0,
$$

Informally, since the marginal utility of consumption is always positive, it cannot be optimal for the present value of agents' 'end of horizon' net financial assets to be strictly positive. The first order conditions have been written as equilibrium conditions: $Y_{t}$ has been set equal to $C_{t}$ as it must be in equilibrium since there is no government spending, and desired asset stocks have been set equal to actual asset stocks.

We assume that productivity is constant $\left(\rho_{t}=\rho\right)$ except in section 6.3. Under this assumption, the four equilibrium conditions (4), (5), (6), and (7) reduce to the Fisher equation, the money market equilibrium condition, the output determination equation, and the transversality condition:

$$
\begin{gathered}
I_{t}=R \Pi_{t+1} \\
I_{t}=\frac{U^{\prime}(\bar{C})}{U^{\prime}(\bar{C})-V^{\prime}\left(m_{t}\right)} \\
\bar{C}=\rho U^{\prime}(\bar{C}) \\
\lim _{t \rightarrow \infty}\left(M_{t}+B_{t}\right) \prod_{k=0}^{k=t-1} I_{k}^{-1}=0,
\end{gathered}
$$

where $R \equiv \frac{1}{\beta}>1$ is the constant gross real interest rate and $\bar{C}$ is the constant flexible-price value of consumption. $I_{t} \leq 0$ is ruled out by (8), given $R, \Pi_{t+1}>0$. In turn, (9) implies that $U^{\prime}(\bar{C})>V^{\prime}\left(m_{t}\right)$, so depending on the functional form of $V^{\prime}\left(m_{t}\right)$ there may be a lower bound on $m_{t}$ that is greater than zero. Since $U^{\prime}(\bar{C})>0$ and $V^{\prime}\left(m_{t}\right) \geq 0$, (9) implies $I_{t} \geq \Omega \geq 1$, where $\Omega$ is the lower bound on $I_{t}$ implied by $V^{\prime}\left(m_{t}\right)$. Since $R>1$ and $I_{t} \geq \Omega$, (8) also implies $\Pi_{t} \geq \frac{\Omega}{R}$. 


\subsection{Policy}

We assume that fiscal policy determines the total amount of nominal government bonds outstanding, $D_{t}$, through control of the budget deficit inclusive of interest payments. Monetary policy determines whether these bonds are held by the monetary authority as a match for the money supply, $M_{t}$, or directly by the public, $B_{t}$, through control of open-market operations. The consolidated government balance sheet implies that $D_{t}=M_{t}+B_{t}$. Most of this paper is devoted to the analysis of determinacy under alternative monetary-policy rules which are specified below. Except in section 6 , we assume that fiscal policy is conducted so that (11) holds for any path of the nominal interest rate. ${ }^{9}$ Fiscal policy and equation (11), therefore, may be disregarded until that section.

So that we can discuss indeterminacy in our stripped-down model, we assume that there is a target equilibrium $(T E)$ with a target value for inflation $\left(\Pi^{*}\right)$ given by $\Pi^{*}>\frac{\Omega}{R}$ because of considerations not included in the model. Since the target nominal interest rate $\left(I^{*}\right)$ must satisfy $I^{*}=R \Pi^{*}$, it is given by $I^{*}>\Omega$. Absent such considerations, the optimal values for $\Pi_{t}$ and $I_{t}$ would be $\frac{\Omega}{R}$ and $\Omega$, respectively. Our main focus is on the possible existence of below-target equilibria $(B T E)$. We define $B T E$ as weakly increasing or decreasing paths for inflation and the interest rate along which they are always below $\Pi^{*}$ and $I^{*}$ respectively, and are either constant at, asymptotically approach, or eventually reach values represented by $\Pi^{B T E}$ and $I^{B T E}$, respectively, where $I^{*}>I^{B T E}=R \Pi^{B T E} \geq \Omega$.

\subsection{Money demand and lower bounds on the interest rate}

We consider two particular specifications of money demand. Under both specifications the gross nominal interest rate has a lower bound (possibly one). Equation (9) implies

$$
I_{t}=\frac{U^{\prime}(\bar{C})}{U^{\prime}(\bar{C})-V^{\prime}\left(m_{t}\right)} \geq \frac{U^{\prime}(\bar{C})}{U^{\prime}(\bar{C})-\lim _{m_{t} \rightarrow \infty} V^{\prime}\left(m_{t}\right)}=\Omega \geq 1
$$

Of course, a lower bound of one for $I_{t}$ implies a lower bound of zero for the net nominal interest rate.

The lower bound $\Omega$ may be unattainable or attainable. To model an attainable lower bound $(A L B)$ for $I_{t}$, we assume that the utility of real balances is given by

$$
V\left(m_{t}\right)=\left\{\begin{array}{cl}
\underline{V}^{\prime} m_{t}-\frac{1}{2}\left(\bar{m}-m_{t}\right)^{2} & \text { for } m_{t} \leq \bar{m} \\
\underline{V^{\prime}} m_{t} & \text { for } m_{t}>\bar{m}
\end{array}, \quad \bar{m}>0\right.
$$

\footnotetext{
${ }^{9}$ This means that (except in section 6) fiscal policy is assumed to be Ricardian according to the definition of Benhabib, Schmitt-Grohe, and Uribe (1998). A sufficient condition for (11) to hold is that the gross growth rate of total government debt is low enough. Since the nominal interest rate enters equation (11), the maximum permissible growth rate depends on monetary policy and the rest of the model.
} 
As before, $\underline{V}^{\prime} \geq 0$ represents the minimum marginal utility of real balances. Equation (12) implies

$$
I_{t}=\left\{\begin{array}{cc}
\frac{U^{\prime}(\bar{C})}{U^{\prime}(\bar{C})-\left(\bar{m}-m_{t}\right)-\underline{V}^{\prime}} & \text { for } m_{t} \leq \bar{m} \\
\frac{U^{\prime}(\bar{C})}{U^{\prime}(\bar{C})-\underline{V}^{\prime}} & \text { for } m_{t}>\bar{m}
\end{array}\right\} \geq \frac{U^{\prime}(\bar{C})}{U^{\prime}(\bar{C})-\underline{V^{\prime}}}=\Omega^{A L B},
$$

To model an unattainable lower bound $(U L B)$, we assume that the utility of real balances is given by

$$
V\left(m_{t}\right)=\underline{V}^{\prime} m_{t}+\gamma \ln m_{t} \quad \gamma>0, \quad \underline{V^{\prime}} \geq 0, \quad m_{t}>\frac{\gamma}{U^{\prime}(\bar{C})-\underline{V^{\prime}}}
$$

where $\underline{V}^{\prime}$ represents the lower limit of the marginal utility of real balances. With this functional form, equation (9) implies

$$
I_{t}=\frac{U^{\prime}(\bar{C})}{U^{\prime}(\bar{C})-\frac{\gamma}{m_{t}}-\underline{V^{\prime}}}>\frac{U^{\prime}(\bar{C})}{U^{\prime}(\bar{C})-\lim _{m_{t} \rightarrow \infty} \frac{\gamma}{m_{t}}-\underline{V^{\prime}}}=\frac{U^{\prime}(\bar{C})}{U^{\prime}(\bar{C})-\underline{V^{\prime}}}=\Omega^{U L B}
$$

Money-demand functions with an $A L B$ and an $U L B$ are represented in figure $1 .^{10}$ In both cases, $\Omega=1$ if and only if $\underline{V}^{\prime}=0$. With an $A L B$ there is a liquidity trap, as conventionally defined, at the lower bound. Purchases of bonds with money can not lower the interest rate. With an $U L B$ there is never a liquidity trap. Purchases of bonds with money can always lower the interest rate, if only by an infinitessimal amount.

From (16), (14), and $I>0$ (from (4)) we know that there exists a minimum level for real money balances denoted by $\underline{m}: m \geq \underline{m}=\max \left\{\bar{m}+\underline{V^{\prime}}-U^{\prime}(\bar{C}), 0\right\}$ with an $A L B$ model, and $m>\underline{m}=\frac{\gamma}{U^{\prime}(\bar{C})-\underline{V}^{\prime}}$ with an $U L B$. In order for $\lim _{m \rightarrow \underline{m}} I=\infty$ in the $A L B$ model, we need $\bar{m}+\underline{V}-U^{\prime}(\bar{C}) \geq 0$.

\section{Interest-rate rules and BTE}

We begin by assuming that monetary policy takes the form of interest-rate rules and consider two examples. The general form of the interest-rate rules is

$$
I_{t}=g\left(I^{*}, \frac{Y_{t}}{\bar{Y}}, \frac{\Pi_{t}}{\Pi^{*}}\right)
$$

where $\Pi^{*}$ is the target-equilibrium $(T E)$ inflation rate and $\bar{Y}=\bar{C}$ is the flexible-price output level. With flexible prices, output is always at its flexible-price level , $Y_{t}=\bar{Y}$, so from now on we omit $\frac{Y_{t}}{Y}$. We assume that the elasticity of the interest rate with respect to the inflation rate evaluated at the target inflation rate is greater than one. If

\footnotetext{
${ }^{10}$ For figure $1, \underline{V}^{\prime}=0.001, \gamma=1, \bar{m}=2$, and $U^{\prime}(\bar{C})=1$.
} 
$\Pi_{t}=\Pi^{*}$, then $I_{t}=I^{*}$. In this and the following section, we assume that the interestrate rule is at least weakly increasing in the inflation rate and that the interest rate has a lower bound, either a preference-determined lower bound or a policy-determined lower bound. A preference-determined lower bound might exist because of a liquidity trap. A policy-determined lower bound might exist, for example, because the monetary authority wants to keep money market funds economic. ${ }^{11}$ Under these assumptions, interest-rate rules are associated with two steady-state equilibria: a $T E$ with $\Pi_{t}=\Pi^{*}$ and a $B T E$, where $\Omega / R \leq \Pi^{B T E}<\Pi^{*}$ and $\Omega \leq I^{B T E}<I^{*}$.

\subsection{A preference-determined lower bound}

First, consider the case of an interest-rate rule under which the interest rate may go all the way to the preference-determined lower bound, $\Omega^{A L B}$, associated with an $A L B$ money-demand function: ${ }^{12}$

$$
I_{t}=\max \left[\Omega^{A L B}, I^{*}\left(\frac{\Pi_{t}}{\Pi^{*}}\right)^{\lambda}\right], \quad \lambda>1
$$

The piecewise log-linear rule (18) is globally (weakly) increasing in the inflation rate, and the elasticity of the interest rate with respect to the inflation rate in the strictly increasing part is $\lambda>1 .{ }^{13}$ We refer to this case as the liquidity-trap case.

The Fisher equation (8), the interest-rate rule (18), and $I^{*}=R \Pi^{*}$ imply a loglinear difference equation in $\Pi_{t}$ when $I_{t}>\Omega^{A L B}$ :

$$
\begin{aligned}
& \Pi_{t+1}=\frac{I^{*}}{R}\left(\frac{\Pi_{t}}{\Pi^{*}}\right)^{\lambda}=\left(\Pi^{*}\right)^{1-\lambda}\left(\Pi_{t}\right)^{\lambda} \\
& \hat{\Pi}_{t+1}=(1-\lambda) \hat{\Pi}^{*}+\lambda \hat{\Pi}_{t}
\end{aligned}
$$

where variables with hats over them represent logarithms. The solution is

$$
\hat{\Pi}_{t+k}=\hat{\Pi}^{*}+(\lambda)^{k}\left[\hat{\Pi}_{t}-\hat{\Pi}^{*}\right]
$$

One possible steady-state equilibrium is inflation equal to the target rate. If one could disregard the lower bound on the interest rate, this would be the only equilibrium. Deviations from the inflation target would result in explosive or implosive paths of inflation since $\lambda>1$.

However, equation (20) applies only when it calls for an interest rate at or above $\Omega^{A L B}$. The inflation rate cannot decline forever. If the inflation rate given by $(20)$

\footnotetext{
${ }^{11}$ For these funds to survive, there must be some spread between the market rates they earn and the deposit rates they pay as noted by Bernanke and Reinhart (2004).

${ }^{12}$ In this sense, the rule (18) is similar to the one used in Schmitt-Grohe and Uribe (2000) and in the appendix of Benhabib, Schmitt-Grohe, and Uribe (2001a).

${ }^{13}$ We use an interest-rate rule of the form (18) so that the inflation-rate term in the strictly increasing range is directly comparable to the inflation-rate term in the money-supply rule (28).
} 
calls for an interest rate below $\Omega^{A L B}$, the inflation rate is determined by the Fisher equation (8) together with $I_{t}=\Omega^{A L B}$ instead of by (20). That is, the inflation rate will stop declining when it is equal to its lower bound:

$$
\Pi_{t+1}=\frac{\Omega^{A L B}}{R}
$$

The difference equation reflecting the lower bound has the form shown in figure $2:^{14}$

$$
\Pi_{t+1}=\max \left[\frac{\Omega^{A L B}}{R},\left(\Pi^{*}\right)^{1-\lambda}\left(\Pi_{t}\right)^{\lambda}\right]
$$

The list of equilibria as indexed by $\Pi_{0}$ is

1. $\Pi_{0}=\Pi^{*}$. Steady-state $T E$.

2. $\Pi_{0} \in\left\langle\frac{\Omega^{A L B}}{R}, \Pi^{*}\right\rangle . \Pi_{t}$ decreases to $\frac{\Omega^{A L B}}{R}$ in finite time.

3. $\Pi_{0}=\frac{\Omega^{A L B}}{R}$. Steady-state $B T E$ equilibrium.

4. $\Pi_{0} \in\left\langle 0, \frac{\Omega^{A L B}}{R}\right\rangle$. Equilibria with $\Pi_{0}<\Pi_{t}=\frac{\Omega^{A L B}}{R}, t>0 .{ }^{15}$

Along any $B T E$ path, the inflation rate eventually reaches $\frac{\Omega^{A L B}}{R}$ so that $I_{t}$ reaches its liquidity-trap value $\Omega^{A L B}$ at which the levels of the nominal and real money supplies are indeterminate. ${ }^{16}$ Hence, the number of equilibria is even larger than indicated above. Let the liquidity trap be reached in period $n$ at price level $P_{n}$, given a particular initial $P_{0}$. There is an infinity of equilibria associated with each initial $P_{0} \in\left\langle 0, \Pi^{*} P_{-1}\right\rangle$. Once the liquidity trap is reached, the set of possible paths for $M_{k}$, $k \geq n$ includes all paths for which $\frac{M_{k}}{P_{k}} \in[\bar{m}, \infty\rangle, k \geq n$ since agents are indifferent between money and bonds.

There may be more equilibria than those listed above. Beginning on any initial inflation rate above $\Pi^{*}$ the inflation rate follows follows a divergent path. Such divergent paths have been referred to as speculative hyperinflations, for example, by Obstfeld and Rogoff, who have discussed ways of precluding them. ${ }^{17}$ Throughout this paper we assume that paths with ever increasing inflation are precluded.

For the sake of comparison, we briefly consider the case of an interest-rate peg in which $\lambda=0$ and the difference equation in figure 2 is a horizontal line. Suppose

\footnotetext{
${ }^{14}$ For figure $2, \Pi^{*}=1.025, \Omega^{A L B}=1.001,1 / R=0.975$, and $\lambda=2$.

${ }^{15}$ The initial inflation rate is not constrained by the lower bound $\Omega^{A L B} / R$. The reason is that the constraint on the inflation rate is implied by the Fisher equation in combination with the interest rate given by the interest-rate rule. The Fisher equation has no implications for the initial price level or the inflation rate $\frac{P_{0}}{P_{-1}}=\Pi_{0}$, but it has implications for the inflation rate $\frac{P_{1}}{P_{0}}$. Hence, $\Pi_{1} \geq \Omega^{A L B} / R$.

${ }^{16}$ Otherwise, the nominal money supply is determined by the nominal interest rate and the moneydemand function, given the unique inflation rate associated with the TE.

${ }^{17}$ See Obstfeld and Rogoff (1983) and Obstfeld and Rogoff (1986).
} 
it is announced that $I_{t}$ will equal $I^{*}$ in period $t$ and all future periods. The Fisher equation (8), implies that $I^{*}$ would be associated with $\Pi^{*}$ from period $t+1$ on. However, this interest-rate rule would not pin down the initial inflation rate. There would be a continuum of equilibria, indexed by the initial inflation rate $\Pi_{t} \in\left\langle 0, \Pi^{*}\right\rangle$. However, if the monetary authorities specify the initial level of the money supply in addition to the interest-rate peg, the initial inflation rate is determinate, since there is a unique level of real balances associated with $I_{t}=I^{*}$.

\subsection{A policy-determined lower bound}

Now consider interest-rate rules designed to keep the gross nominal interest rate from falling below a policy-determined lower bound, $\Lambda$, that may be above $\Omega$. The policy-determined lower bound may be attainable, $\Lambda^{A L B}$, or unattainable, $\Lambda^{U L B}$. For example, with the interest-rate rule

$$
I_{t}=\max \left[\Lambda^{A L B}, I^{*}\left(\frac{\Pi_{t}}{\Pi^{*}}\right)^{\lambda}\right], \quad \Lambda^{A L B} \geq \Omega, \quad \lambda>1
$$

the policy-determined lower bound is attainable. This rule and the difference equation in inflation that it implies are identical to the ones considered in the last subsection except that the lower bounds on the interest rate and inflation are determined by policy, not by preferences. The rule is implementable with both $A L B$ money demand $\left(\Lambda^{A L B} \geq \Omega^{A L B}\right)$ and with $U L B$ money demand $\left(\Lambda^{A L B}>\Omega^{U L B}\right)$. The entire list of possible equilibria is given by items 1 through 4 in the last subsection except that $\Lambda^{A L B}$ replaces $\Omega^{A L B}$ everywhere. In contrast to the liquidity trap case, when $\Pi_{t}$ reaches $\frac{\Lambda^{A L B}}{R}$ along a $B T E$ path, real balances and nominal balances are uniquely determined. ${ }^{18}$

It is useful to consider a rule that is very similar to the continuously differentiable rules used in the seminal papers on the existence of $B T E$ :

$$
\begin{gathered}
I_{t}=\left(I^{*}-\Lambda^{U L B}\right)\left(\frac{\Pi_{t}}{\Pi^{*}}\right)^{\frac{\lambda I^{*}}{I^{*}-\Lambda^{U L B}}}+\Lambda^{U L B}, \quad \Pi_{t}>0 \\
I^{*}=R \Pi^{*}>\Lambda^{U L B} \geq \Omega \geq 1, \quad \lambda>1
\end{gathered}
$$

\footnotetext{
${ }^{18}$ Consider the family of interest-rate rules given by

$I_{t}=\max \left[\Upsilon,\left(I^{*}-\Upsilon\right)\left(\frac{\Pi_{t}-\Upsilon / R}{\Pi^{*}-\Upsilon / R}\right)^{\lambda R\left[\frac{\Pi^{*}-\Upsilon / R}{I^{*}-\Upsilon}\right]}+\Upsilon\right], \quad I^{*}>\Upsilon \geq \max \left(\Omega^{A L B}, \Lambda^{A L B}, 1\right), \quad \lambda>1$
}

With this family, the strictly increasing part of the difference equation for $\Pi_{t}$ begins at the point $\left(\frac{\Upsilon}{R}, \frac{\Upsilon}{R}\right)$ on the $45^{\circ}$ line in $\left(\Pi_{t+1}, \Pi_{t}\right)$ space. If $\Upsilon=1$, the implied difference equation is qualitatively identical to the one plotted in Figure 2.4 of Woodford (2003). 
This rule has a policy-determined lower bound that is unattainable. ${ }^{19}$ It is implementable with both $A L B$ and $U L B$ money-demand functions. The interest rate rises with inflation, and the response is greater the higher is inflation. ${ }^{20}$ As before, the elasticity of the interest rate with respect to the inflation rate at $\Pi^{*}$ is $\lambda>1$.

With the rule (24), there must be two steady-state equilibrium inflation rates: one is $\Pi^{*}$ and the other is $\Pi^{B T E}$ which is below $\Pi^{*}$ and above $\Lambda^{U L B} / R$ but which may or may not involve deflation. Combining the rule (24) with the Fisher equation (8) yields a difference equation in inflation of the form plotted in figure $3:^{21}$

$$
\Pi_{t+1}=\frac{1}{R}\left[\left(I^{*}-\Lambda^{U L B}\right)\left(\frac{\Pi_{t}}{\Pi^{*}}\right)^{\frac{\lambda R}{I^{*}-\Lambda^{U L B}}}+\Lambda^{U L B}\right]
$$

This equation is a convex function that has a lower bound of $\frac{\Lambda^{U L B}}{R} \geq \frac{\Omega}{R}$ and that crosses the $45^{\circ}$ degree line from below at $\Pi_{t+1}=\Pi_{t}=\Pi^{*}$ where its slope is greater than one:

$$
\left.\frac{d \Pi_{t+1}}{d \Pi_{t}}\right|_{\Pi_{t}=\Pi^{*}}=\lambda>1
$$

that is, $\Pi^{*}$ is an unstable steady state equilibrium. In addition its slope approaches zero as $\Pi_{t}$ approaches 0 from above and rises continuously with $\Pi_{t}$ :

$$
\frac{d \Pi_{t+1}}{d \Pi_{t}}=\lambda\left(\frac{\Pi_{t}}{\Pi^{*}}\right)^{\frac{\lambda R}{I^{*}-\Lambda}-1}>0
$$

Therefore, it must intersect the $45^{\circ}$ line a second time at a point below $\Pi^{*}$ represented by $\Pi^{B T E}$ where its slope is less than one. ${ }^{22}$ That is, $\Pi^{B T E}$ is a stable equilibrium with deflation $\left(\Lambda^{U L B} / R<\Pi^{B T E}<1\right)$, stable prices $\left(\Lambda^{U L B} / R<\Pi^{B T E}=1\right)$, or inflation $\left(1<\Pi^{B T E}\right)$.

There is a continuum of equilibria, indexed by $\Pi_{0}$. Each $\Pi_{0}$ is associated with one of the two possible steady-state inflation rates.

\footnotetext{
${ }^{19}$ The continuous-time policy rule used in Benhabib, Schmitt-Grohe, and Uribe (2001b) and the main text of Benhabib, Schmitt-Grohe, and Uribe (2001a) has a policy-determined unattainable lower bound. The discrete-time analogue of this rule is

$$
I_{t}=\left(I^{*}-\Lambda^{U L B}\right) \exp \left[\frac{R A}{I^{*}-\Lambda^{U L B}}\left(\Pi_{t}-\Pi^{*}\right)\right]+\Lambda^{U L B}, \quad A>1
$$

We employ the rule (24) because it is directly comparable to the other interest-rate rules and the money-supply rules (28) used in this paper. Rule (24) is also used by Evans and Honkapohja (2003), who assume that $\Lambda^{U L B}=1$.

20 That is

$$
\frac{d I_{t}}{d \Pi_{t}}=\lambda R\left(\frac{\Pi_{t}}{\Pi^{*}}\right)^{\frac{\lambda I^{*}}{I^{*}-\Lambda}-1}>0, \quad \frac{d^{2} I_{t}}{d \Pi_{t}^{2}}=\left(\frac{\lambda I^{*}}{I^{*}-\Lambda}-1\right)\left(\frac{\Pi_{t}}{\Pi^{*}}\right)^{-1} \frac{d I_{t}}{d \Pi_{t}}>0
$$

${ }^{21}$ For figure $3, \Pi^{*}=1.025,1 / R=0.975, \Lambda^{U L B}=1.02$, and $\lambda=2$.

${ }^{22}$ If $\lambda=1$ there would be a unique steady state at $\Pi_{t}=\Pi^{*}$, but there would be multiple initial equilibrium inflation rates because all paths that start below the target rate would approach it.
} 
1. $\Pi_{0}=\Pi^{*}$ : Steady-state $T E$.

2. $\Pi_{0} \in\left\langle\Pi^{B T E}, \Pi^{*}\right\rangle:$ Non-steady-state $B T E ; \Pi_{t} \rightarrow \Pi^{B T E}$ from above

3. $\Pi_{0}=\Pi^{B T E}:$ Steady-state $B T E$.

4. $\Pi_{0} \in\left\langle 0, \Pi^{B T E}\right\rangle:$ Non-steady-state $B T E ; \Pi_{t} \rightarrow \Pi^{B T E}$ from below. ${ }^{23}$

\section{Indeterminacy under money-growth rules}

\subsection{Indeterminacy with $U L B$ money demand}

When the money-demand function has an $U L B$, money-growth rules are consistent with the existence of both a $T E$ and $B T E$ in which real money balances are forever increasing and the interest rate is approaching its lower bound. ${ }^{24}$

Consider the money-growth rule:

$$
\frac{M_{t} / M_{t-1}}{\Pi^{*}}=\left(\frac{\Pi_{t}}{\Pi^{*}}\right)^{-\tau}, \quad \tau>-1
$$

If $\tau=0$, money grows at the constant target gross growth rate of money which is equal to $\Pi^{*}$. In that case, since $M_{-1}$ and $P_{-1}$ are given, $M_{0}$ is determined by $\Pi^{*}$. If $\tau \neq 0$, there is one $M_{0}$ associated with each $P_{0} \cdot{ }^{25}$ In either case, there will be a range of equilibria, each with its own level of initial real balances.

The Fisher equation (8) and the money market equilibrium condition (9) with the functional form for $V\left(m_{t}\right)$ in equation (15) imply an expression for the inflation rate in terms of real balances:

$$
\Pi_{t}=\left(\frac{1}{R}\right) \frac{U^{\prime}(\bar{C})}{U^{\prime}(\bar{C})-\left(\frac{\gamma}{m_{t-1}}+\underline{V^{\prime}}\right)}
$$

Furthermore, the money-growth rule can be rewritten as

$$
m_{t}=m_{t-1}\left(\Pi_{t}\right)^{-(1+\tau)} \Pi^{* 1+\tau}
$$

Combining (30) and (29), yields a difference equation in real balances,

$$
m_{t}=m_{t-1}\left(\Pi^{*}\right)^{1+\tau}\left[\left(\frac{1}{R}\right) \frac{U^{\prime}(\bar{C})}{U^{\prime}(\bar{C})-\frac{\gamma}{m_{t-1}}-\underline{V^{\prime}}}\right]^{-(1+\tau)}
$$

\footnotetext{
${ }^{23} \Pi_{0}$ can be lower than $\frac{\Omega^{U L B}}{R}$, see footnote 15 .

${ }^{24}$ This possibility is pointed out, for example, in Woodford (1994), Woodford (2003), Christiano and Rostagno (2001), and Benhabib, Schmitt-Grohe, and Uribe (2001a)). We begin with the case of $U L B$ money demand because it is somewhat simpler.

${ }^{25}$ With $0>\tau>-1$, nominal balances increase when the inflation rate is above target. For further discussion of this case, see footnote 27 .
} 
with the form plotted in figure $4 .^{26}$ Given the definition of $\Omega^{U L B}$ in equation (16), it follows that the term in square brackets $\left(\Pi_{t}\right)$ approaches $\Omega^{U L B} / R$ as $m_{t-1} \rightarrow \infty$. Therefore, the growth rate of real balances $\left(m_{t} / m_{t-1}\right)$ approaches $\left(\frac{R \Pi^{*}}{\Omega^{U L B}}\right)^{1+\tau}>1$ for $\tau>-1 .{ }^{27}$

The unique steady-state solution for equation (31) is

$$
m^{*}=\frac{\gamma}{U^{\prime}(\bar{C})-\frac{U^{\prime}(\bar{C})}{I^{*}}-\underline{V^{\prime}}}=\frac{\gamma}{\frac{I^{*}-1}{I^{*}} U^{\prime}(\bar{C})-\underline{V^{\prime}}}
$$

If the steady-state level of real balances is to be positive, it must be that

$$
I^{*}>\frac{U^{\prime}(\bar{C})}{U^{\prime}(\bar{C})-\underline{V^{\prime}}} \equiv \Omega^{U L B}
$$

The money-growth rule may be associated not only with the $T E$, but also with a range of $B T E$ in which inflation declines forever and approaches the limit $\Omega^{U L B} / R$. The equilibria may be indexed by $m_{0}$ :

1. $m_{0}=m^{*}$ : Steady state $T E$ with $\Pi_{0}=\Pi_{t}=\Pi^{*}$.

2. $m_{t}>m^{*}: B T E$ with positive growth in $m_{t}, \Pi_{0} \in\left\langle 0, \Pi^{*}\right\rangle$ and $\Pi_{t} \rightarrow \Omega^{U L B} / R$ from above, $t>0$.

The money-growth rule has a representation as an interest-rate rule that is related to but somewhat different from the one discussed in section 3.2. ${ }^{28}$

\subsection{Indeterminacy with $A L B$ money demand}

With $A L B$ money demand money-growth rules are also consistent with the existence of both a $T E$ and $B T E$. In the $B T E$, real money balances are forever increasing money demand, as with $U L B$ money demand, but the interest rate reaches its lower

\footnotetext{
${ }^{26}$ For figure $4, \tau=2, \Pi^{*}=1.025, \gamma=1, U^{\prime}(\bar{C})=1, \underline{V^{\prime}}=0.001$, and $1 / R=0.975$, so $\underline{m}=$ $\gamma /\left(U^{\prime}(\bar{C})-\underline{V^{\prime}}\right)=1.001$.

${ }^{27} \mathrm{~m}^{*}$ is an unstable steady state since equation (31) and the expression for $\Pi^{*}$ given by (29) imply that for all $\tau>-1$

$$
\left.\frac{d m_{t}}{d m_{t-1}}\right|_{m_{t}=m^{*}}=\left(\Pi^{*}\right)^{1+\tau}\left[\left(\frac{1}{R}\right) \frac{U^{\prime}(\bar{C})}{\left.U^{\prime}(\bar{C})-\frac{\gamma}{m^{*}}-\underline{V^{\prime}}\right)}\right]^{-(1+\tau)}\left[1+\frac{(1+\tau) m^{*} \frac{\gamma}{\left(m^{*}\right)^{2}}}{U^{\prime}(\bar{C})-\frac{\gamma}{m^{*}}-\underline{V^{\prime}}}\right]=1+\frac{R(1+\tau) \gamma \Pi^{*}}{m^{*} U^{\prime}(\bar{C})}>1
$$

${ }^{28}$ Equation (16) can be used to obtain an expression for $m_{t}$ in terms of $I_{t}$. Using this expression and assuming $\underline{V}^{\prime}=0$, it follows from equations (30) and (8) that

$$
\frac{I_{t}-1}{I_{t}}=\frac{I_{t-1}-1}{I_{t-1}}\left(\frac{\Pi_{t}}{\Pi^{*}}\right)^{1+\tau}=\frac{I_{t-1}-1}{I_{t-1}}\left(\frac{I_{t-1}}{R \Pi^{*}}\right)^{1+\tau}=\frac{I_{t-1}-1}{I_{t-1}}\left(\frac{I_{t-1}}{I^{*}}\right)^{1+\tau}
$$
}


bound. The Fisher equation (8) and the $m_{t} \leq \bar{m}$-part of the money-demand function (14) imply an expression for inflation in terms of real balances:

$$
\Pi_{t}=\left(\frac{1}{R}\right)\left[\frac{U^{\prime}(\bar{C})}{U^{\prime}(\bar{C})-\bar{m}+m_{t-1}-\underline{V^{\prime}}}\right]
$$

Combining the money-growth rule (30) with (34) we obtain a difference equation in real balances:

$$
m_{t}=m_{t-1}\left[\left(\frac{1}{R}\right) \frac{U^{\prime}(\bar{C})}{U^{\prime}(\bar{C})-\bar{m}+m_{t-1}-\underline{V^{\prime}}}\right]^{-(1+\tau)} \Pi^{*(1+\tau)}, \quad m_{t-1} \leq \bar{m}
$$

Given the definition of $\Omega^{A L B}$ in equation (14) it follows that as $m_{t-1}$ increases and reaches $\bar{m}$, the term in square brackets $\left(\Pi_{t}\right)$ increases and reaches $\Omega^{A L B} / R$. Therefore, the growth rate of real balances $\left(m_{t} / m_{t-1}\right)$ increases and reaches $\left(\frac{R \Pi^{*}}{\Omega^{A L B}}\right)^{1+\tau}>1$ for $\tau>-1$.

There exists a steady-state equilibrium with positive real balances equal to

$$
m^{*}=\frac{U^{\prime}(\bar{C})}{R \Pi^{*}}+\bar{m}+\underline{V^{\prime}}-U^{\prime}(\bar{C})=\bar{m}+\underline{V^{\prime}}-\left(\frac{I^{*}-1}{I^{*}}\right) U^{\prime}(\bar{C})
$$

under weak conditions that we assume are met. ${ }^{29}$ This equilibrium is a $T E$ in which $\Pi=\Pi^{*}$ and $I=I^{*} \cdot{ }^{30}$ Equation (35) applies only when $m_{t} \leq \bar{m}$. In cases in which $m_{t}>\bar{m}$, the difference equation in real balances is given by (30) with the inflation rate fixed at $\Omega^{A L B} / R$.

Figure 5 is a diagram for the case where $\underline{m}>0$ because $\bar{m}+\underline{V^{\prime}}-U^{\prime}(\bar{C})>0 .{ }^{31}$

The list of equilibria indexed by $m_{0}$ is now

1. $m_{0}=m_{t}=m^{*}: T E$ steady state with $\Pi_{0}=\Pi^{*}$

2. $\bar{m}>m_{0}>m^{*}: B T E$ with $\Pi_{0} \in\left\langle\frac{\Omega^{A L B}}{R}, \Pi^{*}\right\rangle, \Pi_{t}$ reaches $\frac{\Omega^{A L B}}{R}$ from above, $t>0 . m_{t}$ reaches $\bar{m}$ from below,

${ }^{29}$ The positive steady state exists only if $\bar{m}+\underline{V^{\prime}}-\frac{I^{*}-1}{I^{*}} U^{\prime}(\bar{C})>0$ or equivalently $\frac{U^{\prime}(\bar{C})}{U^{\prime}(\bar{C})-\bar{m}-\underline{V^{\prime}}}>I^{*}$. That is, the target interest rate must be smaller than the maximum possible interest rate. For parameter values for which $\lim _{m_{t} \rightarrow \underline{m}} I_{t}=\infty, \bar{m}+\underline{V^{\prime}}-U^{\prime}(\bar{C})=\underline{m}>0$, so the condition is definitely met. In order to exist, the strictly positive steady state equilibrium must also satisfy $\underline{m} \leq m^{*} \leq \bar{m}$, which means that $\bar{m}+\underline{V^{\prime}}-U^{\prime}(\bar{C}) \leq m^{*}=\bar{m}+\underline{V^{\prime}}-\left(\frac{I^{*}-1}{I^{*}}\right) U^{\prime}(\bar{C}) \leq \bar{m}$. This condition is always satisfied as long as $\underline{V}^{\prime}$ is not too large.

${ }^{30} \mathrm{~m}^{*}$ is an unstable steady state since (36) and the definition of $I^{*}$ imply

$$
\left.\frac{d m_{t}}{d m_{t-1}}\right|_{\bar{m}=m^{*}}=1+(1+\tau) m^{*} \Pi^{*} \frac{I^{*}}{U^{\prime}(\bar{C})}>1
$$

${ }^{31}$ For figure $5, \underline{V^{\prime}}=0.001, \tau=2, \bar{m}=1.5, U^{\prime}(\bar{C})=1,1 / R=0.975, \Pi^{*}=1.025$, so $\underline{m}=0.5$. 
3. $m_{0} \geq \bar{m}: B T E$ with $\Pi_{0} \in\left\langle 0, \frac{\Omega^{A L B}}{R}\right]$ and $\Pi_{t}=\frac{\Omega^{A L B}}{R}, t>0$. The $m_{t}$ growth rate is constant at $\left(\frac{I^{*}}{\Omega^{A L B}}\right)^{1+\tau}$.

There is a second steady-state equilibrium with zero real balances when $\bar{m}+\underline{V^{\prime}}-$ $U^{\prime}(\bar{C}) \leq 0$ so that $\underline{m}=0 .{ }^{32}$ This case is not of particular interest to us because we want to focus on equilibria in which inflation is below target (real balances are above target). However, it is quite important for those considering the existence of hyperinflation equilibria.

The money-growth rule in the $A L B$ model also has a representation as an interestrate rule as long as $m_{t} \leq \bar{m}$. $^{33}$ However, $I=\Omega^{A L B}$ for all $m_{t} \geq \bar{m}$. Hence, the interest-rate rule representation requires an additional specification of policy when $I=\Omega^{A L B}$ in order to uniquely pin down the path of real money balances for each initial $m_{0}$. For example, Eggertson and Woodford (2003) add a rule for money growth that applies whenever the interest rate reaches its lower bound.

\section{Monetary-policy rules that imply uniqueness}

\subsection{A nonmonotonic interest-rate rule}

First, we show that making the interest-rate rule a nonmonotonic function of the inflation rate may insure a unique equilibrium, following up on an observation by Benhabib, Schmitt-Grohe, and Uribe (2001b). Consider the piecewise log-linear interestrate rule

$$
I_{t}=\left\{\begin{array}{cc}
I_{t}^{*}\left(\frac{\Pi_{t}}{\Pi^{*}}\right)^{\lambda} & \text { if } I^{*}\left(\frac{\Pi_{t}}{\Pi^{*}}\right)^{\lambda}>\Omega \\
\widetilde{I}>I^{*} & \text { if } I^{*}\left(\frac{\Pi_{t}}{\Pi^{*}}\right)^{\lambda} \leq \Omega
\end{array}\right.
$$

This rule is similar to the one described in section 3.2, but the interest rate is pegged at $\widetilde{I}>I^{*}$ instead of at the policy-determined lower bound value $\Lambda^{A L B}$. It is feasible with both $A L B$ and $U L B$ money demands, since it never calls for $I_{t}=\Omega$.

The difference equation in the inflation rate that follows from (37) and the Fisher equation (8) is illustrated in figure $6 .{ }^{34}$ Consider a situation where the inflation rate is so low that if $I$ were given by $I^{*}\left(\frac{\Pi}{\Pi^{*}}\right)^{\lambda}$ it would be less than or equal to the lower

\footnotetext{
${ }^{32}$ See section 2.3. In this case (not shown), the line representing the difference equation would start at the origin and have a slope that is below one at the origin, increases until it exceeds one, and is constant for $m_{t}>\bar{m}$.

${ }^{33}$ Using (30),(8) and (14), we get

$$
\frac{I_{t}-1}{I_{t}} U^{\prime}(\bar{C})=\left[\frac{I_{t-1}-1}{I_{t-1}} U^{\prime}(\bar{C})-\left(\underline{V^{\prime}}+\bar{m}\right)\right]\left[\frac{I^{*}}{I_{t-1}}\right]^{1+\tau}+\left(\underline{V^{\prime}}+\bar{m}\right)
$$

${ }^{34}$ For figure $6, \Pi^{*}=1.025,1 / R=0.975, \Omega=1.001, \lambda=2$, and $\tilde{I}=1.05 / 0.975 \approx 1.077$.
} 
bound, $\Omega$. In such a situation, $I_{t}$ jumps up to $\widetilde{I}$. In the next period, the inflation rate must be higher than the target inflation rate given the Fisher equation and the fact that $\widetilde{I}>I_{t}^{*}$. But such a path is not a possible solution, because it implies that the inflation rate increases without limit. Hence, the economy cannot start out on a path of declining inflation.

\subsection{A monotonic but asymmetric interest-rate rule}

Next, we demonstrate that there is an asymmetric interest-rate rule that is associated with a unique steady-state inflation rate and a determinate price level. Consider the following rule ${ }^{35}$,

$$
I_{t}=\left(I_{t}^{*}\right)\left(\frac{\Pi_{t}}{\Pi^{*}}\right)^{\lambda}\left(\frac{\Pi_{t+1}}{\Pi^{*}}\right)^{\gamma}
$$

Combining equation (38) with the Fisher equation (8) and using $I_{t}^{*}=R \Pi^{*}$, give a first-order difference equation in the inflation rate,

$$
\Pi_{t+1}=\Pi^{* \frac{1-\lambda-\gamma}{1-\gamma}} \Pi_{t}^{\frac{\lambda}{1-\gamma}}
$$

Taking logs, we have

$$
\widehat{\Pi}_{t+1}=\alpha_{0} \widehat{\Pi}^{*}+\alpha_{1} \widehat{\Pi}_{t}
$$

where $\alpha_{0}=\frac{1-\lambda-\gamma}{1-\gamma}$ and $\alpha_{1}=\frac{\lambda}{1-\gamma}$. With $\lambda$ and $\gamma$ chosen so that $\left|\alpha_{1}\right|>1$, the equation is unstable and the unique solution for $\Pi_{t}$ is $\Pi^{*}$.

The rule (38) implies asymmetric responses under the following assumptions:

- If $\Pi_{t}<\Pi^{*}, 2>\gamma>1$ and $\lambda>1$, so that $\alpha_{0}>1$ and $\alpha_{1}<-1$.

- If $\Pi_{t}>\Pi^{*}, \gamma=0$ and $\lambda>1$, so that $\alpha_{0}<0$ and $\alpha_{1}>1$.

Under these assumptions, the rule calls for a stronger response to expected future inflation when current inflation is below target.

With the asymmetric rule the difference equation for inflation (39) has the form shown in figure $7 .^{36}$ In contrast with the symmetric rule (19), the asymmetric rule (39) implies a difference equation for inflation for which $\Pi_{1} \geq \Pi^{*}$ no matter how low the value of $\Pi_{0}$. $\Pi^{*}$ is a unique steady-state equilibrium, and $\Pi_{0}=\Pi^{*}$ is the only equilibrium. ${ }^{37}$ If the initial inflation rate is in the interval $\Pi_{0} \in\left\langle 0, \Pi^{*}\right\rangle$, the economy embarks on a path with ever-increasing inflation. The part of the difference equation that applies when $\Pi_{t} \in\left\langle 0, \Pi^{*}\right\rangle$ implies $\Pi_{1}>\Pi^{*}$, and the inflation rate continues to increase because the part that applies when $\Pi_{t} \in\left[\Pi^{*}, \infty\right\rangle$ is now relevant.

\footnotetext{
${ }^{35}$ Benhabib, Schmitt-Grohe, and Uribe (2001c) also consider interest-rate rules where the interest rate responds to both current and future inflation, but in a different context.

${ }^{36}$ For figure $7, \lambda=2, \Pi^{*}=1.025$, and $1 / R=0.975 . \gamma=1.5$ when $\Pi_{t}<\Pi^{*}$, and $\gamma=0$ otherwise.

${ }^{37}$ All it takes for equation (39) to be associated with a unique steady-state $T E$ is that $\alpha_{1}<-1$ when $\Pi_{t}<\Pi^{*}$ and $\alpha_{1}>1$ when $\Pi_{t}>\Pi^{*}$. One could, for example, let $\gamma=0$ so that there was zero response to future inflation, and vary $\lambda$ to meet these requirements.
} 


\subsection{A nonmonotonic money-growth rule}

Finally, we demonstrate that a nonmonotonic money-growth rule can work analogously to the nonmonotonic interest-rate rule in section 5.1. We assume a moneygrowth rule of the form

$$
M_{t}=\left\{\begin{array}{ccc}
\left(\frac{\Pi_{t}}{\Pi^{*}}\right)^{-\tau} \Pi^{*} M_{t-1} & \tau>-1 & \text { if } m_{t-1}<\bar{m} \\
\frac{\alpha \Omega^{A L B}}{R} P_{t-1} m^{*} & \alpha<1 & \text { if } m_{t-1} \geq \bar{m}
\end{array}\right.
$$

and an $A L B$ money demand. The nonmonotonic money-growth rule implies a discontinuous difference equation in real money balances of the form shown in figure $8 .^{38}$

The top relationship in equation (41) is a rewrite of the money-growth rule (28) and $m^{*}$ is the steady-state level of real money balances when following that relationship:

$$
m^{*} \equiv \bar{m}+\underline{V^{\prime}}-\left(\frac{I^{*}-1}{I^{*}}\right) U^{\prime}(\bar{C})
$$

The second part of (41) tells us that the level of real balances in period $t$ will be lower than the steady-state $m^{*}$ level if $m_{t-1} \geq \bar{m}$. To see this, note that the lower bound on the inflation rate is $\Omega^{A L B} / R$. Hence, $P_{t} \geq \frac{\Omega^{A L B}}{R} P_{t-1}$. With $\alpha<1$, real balances must then be lower than $m^{*}$ in period $t$. BTE are precluded because real balances jump below $m^{*}$ as soon as they would reach or exceed the level that applies in a liquidity trap. And when the real balances have reached such a low level, they continue to decline according to the difference equation in real balances, equation (35). Hence, the initial price level at $t$ will be uniquely pinned down at $P_{t}=\Pi^{*} P_{t-1}$.

\section{Fiscal policy and BTE}

\subsection{Fiscal policy can always preclude BTE}

There is always a fiscal policy that precludes BTE no matter what the monetary policy rule. Fiscal policy determines the path of total nominal government debt measured as total nominal government bonds, $D_{t}$. The consolidated government balance sheet implies that $D_{t}$ must equal the money supply (which equals the government bonds held by the monetary authority) plus government bonds held by the public:

$$
D_{t} \equiv M_{t}+B_{t}, \quad D_{0} \neq 0 \quad t \geq 0
$$

For simplicity, we devote most of our attention to fiscal policies under which there is a constant gross growth rate $(\Gamma)$ for total government bonds:

$$
D_{t+1}=\Gamma D_{t}
$$

\footnotetext{
${ }^{38}$ For figure $8, \alpha=0.9, \underline{V^{\prime}}=0.001, \tau=2, \bar{m}=1.5, U^{\prime}(\bar{C})=1,1 / R=0.975$, and $\Pi^{*}=1.025$ so that $\underline{m}=0.5$.
} 
where $\Gamma=1$ is the case of a balanced-budget policy.

Fiscal policy and the transversality condition (11) taken together have implications for the possibility of $B T E$. First, consider a candidate steady-state $B T E$ in which the interest rate is constant at $I^{B T E}$. The path $I_{t}=I^{B T E} \forall t$ can be a steady-state equilibrium only if

$$
\lim _{t \rightarrow \infty}\left(\frac{\Gamma}{I^{B T E}}\right)^{t-1} \Gamma D_{0}=0
$$

Therefore if $\Gamma \geq I^{B T E}$, fiscal policy precludes such a path. With our parameterization, $\Gamma<I^{B T E}$ is a necessary condition for fiscal policy to be consistent with steady-state $B T E .^{39}$

One important implication of the previous paragraph, is that if $\Gamma \geq 1$, the Friedman rule $\left(I_{t}=1 \forall t\right)$ cannot be implemented exactly under any type of monetary policy. This result for the case of $\Gamma=1$ is obtained by Schmitt-Grohe and Uribe (2000) in cases in which the monetary-policy rule is either an interest-rate rule or a money-growth rule. Another important implication is that if $I^{B T E}>1$, there may be $B T E$ with small deficits $\left(I^{B T E}>\Gamma>1\right)$.

Next, consider a candidate $B T E$ path on which the interest-rate path is some weakly decreasing sequence $\left\{I_{k}\right\}$ with $\lim _{k \rightarrow \infty} I_{k}=I^{B T E}$. Let $\left\{I_{k}\right\} \equiv\left\{\Theta_{k} I^{B T E}\right\}$, where $\left\{\Theta_{k}\right\}$ is a weakly decreasing sequence with $\lim _{k \rightarrow \infty} \Theta_{k}=1$. Let the value of $\Theta_{k}$ at some time $\hat{t}$ given by $\Theta_{\hat{t}}>1$ be arbitrarily close to one. This sequence of interest rates can be an equilibrium only if

$$
\lim _{t \rightarrow \infty} D_{0} \Gamma^{t} \Pi_{k=\hat{t}}^{k=t-1}\left[\Theta_{k}^{-1}\left(I^{B T E}\right)^{-1}\right]=0
$$

The condition (46) cannot hold if $\Gamma>I^{B T E}$ and $\Theta_{\hat{t}}$ is arbitrarily close to one. Therefore, $\Gamma>I^{B T E}$ precludes $B T E$ in which the interest rate asymptotically approaches or eventually reaches $I^{B T E}$. In addition, $\Gamma=I^{B T E}$ precludes equilibria in which $I^{B T E}$ is approached asymptotically if $\lim _{t \rightarrow \infty} \Pi_{k=\hat{t}}^{k=t-1} \Theta_{k}^{-1}>0$. This condition is satisfied if the nominal interest rate approaches $I^{B T E}$ (and hence $\Theta_{k}$ approaches one) fast enough, for example if the nominal interest rate reaches $I^{B T E}\left(\Theta_{k}\right.$ reaches one) in finite time.

The class of fiscal policies for which $I^{*}>\Gamma>I^{B T E}$ is especially interesting. As just shown, this class precludes $B T E$ for any monetary policy. It follows that a combination of a member of this class with a standard interest-rate rule like equation (18) or money-supply rule like equation (28) is sufficient to insure that $\Pi^{*}$ is the unique equilibrium value for the inflation rate. These observations suggest that BTE may not be a matter for concern in OECD countries. Most, if not all, of these countries run positive but relatively small government deficits on average so their fiscal policies

\footnotetext{
${ }^{39}$ Of course, there are many other parameterizations of fiscal policy which are consistent with the existence of $B T E$.
} 
may preclude BTE. This possibility is yet another reminder of the importance of analyzing monetary and fiscal policy jointly. ${ }^{40}$

\subsection{Uniqueness with money growth through transfers}

In subsection 4.2 we show that with an ALB money-demand function, the moneygrowth rule (28) is associated with multiple equilibria. There, as well as in all of the paper before section 6 , we assume that $B_{t}$ can take on any value implied by the open-market purchases used to increase the money supply. In particular, $B_{t}$ can be as negative as necessary, or, in other words, government interest-bearing claims on the public can increase without limit.

In this subsection, we assume that there is a finite lower bound on $B_{t}$ designated by $\underline{B}$ where $-\infty<\underline{B}$; that is, government claims on the public cannot exceed the finite amount $-\underline{B}$. Once this limit is reached, the money supply can be increased only by money-financed transfers ('money rain'). The required policy is best viewed as a combination of fiscal policy and monetary policy: the fiscal authority makes a bond-financed transfer to the private sector, and the monetary authority buys the bonds.

If $B T E$ are to be precluded, the transversality condition (11) implies that $\Pi^{*}$ (the target rate of inflation and money growth) must be chosen so that

$$
\lim _{t \rightarrow \infty}\left(\frac{1}{\Omega^{A L B}}\right)^{t-1}\left[\left(\Pi^{*}\right)^{1+\tau}\left(\frac{\Omega^{A L B}}{R}\right)^{-\tau}\right]^{t} M_{0}+\lim _{t \rightarrow \infty}\left(\frac{1}{\Omega^{A L B}}\right)^{t-1} \underline{B} \neq 0
$$

where $\left(\Pi^{*}\right)^{1+\tau}\left(\frac{\Omega^{A L B}}{R}\right)^{-\tau}$ is the constant rate of growth of nominal balances implied by the money-growth rule when the interest rate is at $\Omega^{A L B}$ so that the inflation rate is $\frac{\Omega^{A L B}}{R}$. The condition (47) can always be met under the not very restrictive assumption that $\left(\Pi^{*}\right)^{1+\tau}\left(\frac{\Omega^{A L B}}{R}\right)^{-\tau} M_{0}+\underline{B} \neq 0$. Since $M_{0}>0$, the first term is strictly positive and either unbounded or bounded at $\left(\Pi^{*}\right)^{1+\tau}\left(\frac{\Omega^{A L B}}{R}\right)^{-\tau} M_{0}$ if $\Pi^{*}$ is chosen so that ${ }^{41}$

$$
\left(\Pi^{*}\right)^{1+\tau}\left(\frac{\Omega^{A L B}}{R}\right)^{-\tau} \geq \Omega^{A L B}
$$

or, equivalently, so that

$$
\Pi^{*} \geq\left(\frac{\Omega^{A L B}}{R}\right) R^{\frac{1}{1+\tau}}
$$

\footnotetext{
${ }^{40}$ An early joint analysis of monetary and fiscal policy is Leeper (1991); more recent analyses include Canzoneri, Cumby, and Diba (2001) and Evans and Honkapohja (2002).

${ }^{41}$ Woodford (2003) and Woodford (1994) restrict attention to the case of $\tau=0\left(\right.$ and $\left.\Omega^{A L B}=1\right)$ and argue that the restriction on the range of the target inflation rate, $\Pi^{*}>1$, necessary to preclude $B T E$ is a limitation of money-supply rules relative to interest-rate rules. However, the condition in equation (48) implies that if $\tau>0$, the authorities can follow a money-supply rule that implies uniqueness and still target a gross inflation rate below $\Omega^{A L B}$. In particular, with $\Omega^{A L B}=1$ one can get arbitrarily close to the Friedman rule by choosing $\tau$ large enough.
} 
The second term is either zero or bounded at $\underline{B}$ as $\Omega^{A L B} \geq 1$. Therefore, (47) is satisfied no matter whether the first term is bounded or not. ${ }^{42}$ Note that equation (49) implies uniqueness can be consistent with $\Pi^{*}<\Omega^{A L B}$ if $\tau>0$ and, in particular, with $\Pi^{*}$ arbitrarily close to its Friedman-rule value of $\frac{1}{R}$ if $\Omega^{A L B}=1$ and $\tau$ is large enough. ${ }^{43}$

\subsection{An illustration of the insufficiency of balanced-budget fiscal policy for precluding $B T E$}

In section 6.1, we show that a balanced-budget policy precludes BTE when the interest rate is always at a lower bound of one. Here we show that a balanced-budget policy may not preclude $B T E$ even if the interest rate is at a lower bound of one infinitely often. We assume that there is regular and perfectly foreseen variation in productivity, e.g. seasonal variation. In our example, there is a BTE in which the interest rate fluctuates between one and a value greater than one.

Consider the following period utility function with time-varying productivity, $\rho_{t}$ :

$$
-(1 / 2)\left(\psi-C_{t}\right)^{2}-\left[1 /\left(2 \rho_{t}\right)\right] Y_{t}^{2}+V\left(m_{t}\right)
$$

Solutions for the model with this utility function can be obtained using the procedure for the constant-productivity case. We report only the results needed to make our point.

Equations (50), (4) and (6) imply that the nominal and real interest rates are given by

$$
I_{t}=R_{t} \Pi_{t+1}, \quad R_{t}=\left(\frac{1}{\beta}\right) \frac{1+\rho_{t+1}}{1+\rho_{t}}
$$

Today's real interest rate, $R_{t}$, is high if productivity increases between today and tomorrow and vice versa. Therefore, the 'target' interest rate, $I_{t}^{*}$, must vary if the inflation rate is always to be at its fixed target, $\Pi^{*}:{ }^{4}$

$$
I_{t}^{*}=R_{t} \Pi^{*}
$$

\footnotetext{
${ }^{42}$ In a model in which the lower bound on the gross interest rate is one, Woodford (1994) shows that a money-growth rule in combination with the condition that $B_{t}=0 \forall t$ is associated with uniqueness as long as gross money growth is equal to or larger than one ( $\Pi^{*} \geq 1$ in our notation). When the public holds no government bonds, money must be increased by money-transfers. A money-growth rule with $\Pi^{*}>\Omega^{A L B}$ then corresponds to the class of fiscal policies discussed in is subsection with $\Gamma>\Omega^{A L B}$, since the nominal growth rate of money is equal to the nominal growth rate of government bonds. Benhabib, Schmitt-Grohe, and Uribe (2001a) show that multiple equilibria are precluded under money-growth rules when $B_{t} \geq 0$. As we have shown the lower bound on $B_{t}$ can be negative. What is needed is that money be supplied with lump-sum transfers instead of open-market operations after some point

${ }^{43}$ Woodford $(1994,2003)$ restricts attention to the case of $\tau=0$ (and $\Omega^{A L B}=1$ ) and argues that the restriction on the range of the target inflation rate, $\Pi^{*}>1$, necessary to preclude $B T E$ is a limitation of money-supply rules relative to interest-rate rules.

${ }^{44} \mathrm{~A}$ similar relation is discussed in Woodford (2001b).
} 
We consider a simple example in which (a) the attainable lower bound on the nominal interest rate is unity, $\Omega^{A L B}=1$, (b) $\rho_{t}$ alternates between a high value $\left(\rho_{\text {even }}\right)$ in even periods and a low value $\left(\rho_{\text {odd }}\right)$ in odd periods,

$$
R_{\text {even }}=\frac{1}{\beta \Delta}<R_{\text {odd }}=\frac{\Delta}{\beta}=R_{\text {even }} \Delta^{2}, \quad \Delta=\frac{1+\rho_{\text {even }}}{1+\rho_{\text {odd }}}>1
$$

and (c) $\Pi^{*}$ is set high enough that $I_{t}^{*} \geq \Omega^{A L B}=1$ for all $R_{t}$ which according to equations (52) and (53) implies that $\Pi^{*}$ must be chosen so that ${ }^{45}$

$$
\Pi^{*} \geq \frac{1}{R_{\text {even }}}>\frac{1}{R_{\text {odd }}}
$$

If $I_{0}$ is at the lower bound of one, equations (51) and (54) imply that $\Pi_{1}=1 / R_{0}=$ $1 / R_{\text {even }} \leq \Pi^{*}$. From the interest-rate rule (18) with a time varying $I_{t}^{*}$ and equation (52), it follows that $I_{1}$ is above the lower bound if

$$
I_{1}=I_{1}^{*}\left(\frac{\Pi_{1}}{\Pi^{*}}\right)^{\lambda}=R_{1} \Pi^{*}\left(\frac{1}{R_{0} \Pi^{*}}\right)^{\lambda}=\Pi^{* 1-\lambda} \frac{R_{\text {odd }}}{R_{\text {even }}^{\lambda}}>1
$$

From equation (53) it follows that the condition (55) is satisfied if

$$
\frac{R_{\text {odd }}}{R_{\text {even }}^{\lambda}}=R_{\text {even }}^{1-\lambda} \Delta^{2}>\Pi^{* \lambda-1}
$$

Given $\Pi^{*}$, condition (56) is met if $\Delta$ is high enough. Both (54) and (56) are met for some admissible parameter values, and we assume that they are met in the rest of this subsection. ${ }^{46}$

$I_{2}$ is at the lower bound again. Given $I_{1}>1$ and $\Pi_{1}=1 / R_{\text {even }}, \Pi_{2}$ is given by the difference equation (19) that applies when $I_{t}>1$ :

$$
\Pi_{2}=\left(\Pi^{*}\right)^{1-\lambda}\left(\Pi_{1}\right)^{\lambda}=\left(\Pi^{*}\right)^{1-\lambda}\left(1 / R_{\text {even }}\right)^{\lambda},
$$

Given the interest-rate rule (18) and inequality (54), $I_{2}$ is

$$
I_{2}=\max \left[1,\left(R_{\text {even }} \Pi^{*}\right)\left(\frac{\Pi^{*(1-\lambda)}\left(1 / R_{\text {even }}\right)^{\lambda}}{\Pi^{*}}\right)^{\lambda}\right]=\max \left[1,\left(R_{\text {even }} \Pi^{*}\right)^{1-\lambda^{2}}\right]=1
$$

\footnotetext{
${ }^{45} \mathrm{~A} \Pi^{*}<\beta / \Delta$ cannot be attained because $I^{*}$ would be below a lower bound of one. As noted by Krugman (1998) being in a liquidity trap in which $I_{t}$ is at its lower bound has only nominal consequences in a flexible-price model but has real consequences in a sticky-price model because output has to adjust. For example, Svensson (2000) considers what happens when $\Pi^{*}$ is too low and how it can credibly be raised.

${ }^{46}$ For example, the combination $\beta=.95, \Delta=1.1, \Pi^{*}=1.06$, and $\lambda=1.5$ satisfy both $(54)$ and (56), since $\Pi^{*}=1.06>0.95 * 1.1=1.045=1 / R_{\text {even }}$ and $\left(1 / R_{\text {even }}\right)^{1-\lambda} \Delta^{2}=(1 / .95 * 1.1)^{0.5} * 1.1^{2}$$$
=1.2369>\left(\Pi^{*}\right)^{\lambda-1}=1.0296 \text {. }
$$ 
By induction, interest rates, real interest rates, and inflation rates are

$$
\begin{array}{ll}
I_{\text {even }}=1 & I_{\text {odd }}=\left(R_{\text {even }} \Pi^{*}\right)^{1-\lambda} \Delta^{2}>1 \\
R_{\text {even }} & R_{\text {odd }}=R_{\text {even }} \Delta^{2}>R_{\text {even }} \\
\Pi_{\text {odd }}=1 / R_{\text {even }} & \Pi_{\text {even }}=\left(R_{\text {even }} \Pi^{*}\right)^{1-\lambda}\left(1 / R_{\text {even }}\right)<1 / R_{\text {even }}
\end{array}
$$

since we are assuming that $R_{\text {even }} \Pi^{*} \geq 1$. The interest rate in odd periods, $I_{\text {odd }}=$ $I_{\text {odd }}^{*}\left(\Pi_{\text {odd }} / \Pi^{*}\right)^{\lambda}$, is high because both the target interest rate and actual inflation rate are high: $I_{\text {odd }}^{*}=R_{\text {odd }} \Pi^{*}$ is high because $R_{\text {odd }}$ is high, and $\Pi_{o d d}=1 / R_{\text {even }}$ is high even though $I_{\text {even }}$ is at the lower bound because $R_{\text {even }}$ is low.

It follows that $B T E$ are possible in our example with variable productivity and a balanced budget. The transversality condition is met because the interest rate alternates between one and a value greater than one. As pointed out by Benhabib, Schmitt-Grohe, and Uribe (2001a), a balanced-budget policy precludes only equilibria in which the central bank commits to keep the interest rate equal to one no matter what happens to inflation.

\section{Concluding remarks}

Under many specifications of monetary policy, standard models may exhibit pricelevel indeterminacy. That is, they may have multiple equilibria that include both a locally-unique steady-state target (inflation-rate) equilibrium $(T E)$ and multiple below-target equilibria ( $B T E$ ), equilibria in which the inflation rate is always below target and is constant or eventually reaches or asymptotically approaches a belowtarget value.

Rules with either the (nominal) interest rate or money growth as instruments are consistent with price-level indeterminacy in the presence of a conventionally-defined liquidity trap, a situation in which bonds and money are perfect substitutes at either a positive or zero nominal interest rate. Interest-rate and money-growth rules may also be consistent with indeterminacy even if there is no liquidity trap for one of two reasons. First, an interest-rate rule may keep the interest rate above a policydetermined lower bound. Second, with either an interest-rate rule or a money-growth rule, money demand may imply a lower bound on the interest rate so that the interest rate cannot be lowered 'enough' even though it can always be lowered somewhat.

We have found that implementing monetary policy by setting money growth instead of the interest rate makes a difference only if the economy is in a liquidity trap and money is injected without open-market operations, e.g. by lump sum transfers. Under these conditions, a money-growth rule, more accurately viewed as a combination of a money-growth and fiscal-policy rules, may preclude $B T E$ when an interest-rate rule does not. 
The above results all apply when the interest rate and money growth respond monotonically to eliminate deviations in the current inflation rate from its target value. We have expanded on the observation made in Benhabib, Schmitt-Grohe, and Uribe (2001b) that a unique steady-state inflation rate may be implied by interestrate rules that are non-monotonic in the current inflation rate and have shown that an analogous result holds for non-monotonic money-growth rules. We also show that a unique steady state inflation rate is implied by an asymmetric interest-rate rule that calls for a response not only to current inflation but also to expected future inflation, with the response to expected future inflation being stronger when the current inflation rate is below target.

Conclusions about determinacy under alternative monetary rules depend on fiscal policy as measured by the growth rate of total nominal government debt. There is always a class of fiscal policies that can preclude $B T E$ no matter what the monetary policy because with those policies $B T E$ paths violate the transversality condition. Balanced budget fiscal policy can preclude $B T E$ if the interest rate is always at a zero lower bound. However, it cannot do so if the lower bound on the interest rate is positive or if productivity is variable even though the interest rate is at a lower bound of zero infinitely often.

As stated in the introduction, it is not yet clear whether the existence of $B T E$ is an important problem or a curiosum. Some have argued that BTE are of little interest for theoretical reasons. McCallum (2001, 2003) uses his 'minimum state variable' criterion as one way of determining which equilibria are of interest. In terms of our model, he shows that the locally-unique $T E$ meets this criterion while the multiplicity of $B T E$ equilibria associated with the below-target steady state, often referred to as 'sun-spot' equilibria, do not. Both McCallum (2001, 2003) and Evans and Honkapohja (2002) use stability under a particular type of learning as an alternative criterion. In terms of our model, they show that the $T E$ is stable under learning while the BTE are not. Although these theoretical arguments are attractive, not all analysts are completely convinced by them.

Our analysis suggests another more practical reason for focusing on the $T E$. The combination of any of a range of small deficits with a standard interest-rate or moneysupply rule guarantees that the $T E$ is the unique equilibrium because the deficit precludes $B T E$. This observation suggests that BTE may not be a matter for concern in most OECD countries. Most of these countries run positive but relatively small government deficits on average so their fiscal policies may preclude BTE. This possibility provides another illustration of the importance of analyzing monetary and fiscal policy jointly.

It might be argued that Japan has been in a $B T E$ for the last several years. Although this argument cannot be rejected out of hand, there is a good reason to question it. Japan has had near-zero interest rates and deflation despite the fact that the growth rate of nominal government debt has exceeded nominal interest rates on 
government debt. That is, according to our analysis, fiscal policy was too expansionary to be consistent with a $B T E$.

Many analysts have concluded that the Japanese situation is better described as a standard 'liquidity-trap equilibrium' (LTE). A LTE could arise, for example, if there were a large negative demand shock in the presence of wage and price inertia. In order for output to be equal to potential it would be necessary for the real interest rate to fall below zero. However, the nominal interest rate could not be driven below zero because of a liquidity trap as conventionally defined. Furthermore, expected inflation might not move in the right direction or by the right amount to reduce the real interest rate as much as is required.

For some policies, appropriateness depends crucially on whether one is concerned about $L T E$ or BTE, but, for others, it does not. For example, it is often suggested that Japan should announce a higher target inflation rate. Raising the target inflation rate (or increasing the money supply even though the interest rate is at the lower bound) can help an economy escape from an LTE by raising expected future inflation thereby lowering the real interest rate. ${ }^{47}$ However, we have shown that this policy cannot help escape from a $B T E$ because the target inflation rate is irrelevant for this type of equilibrium. In contrast, no matter which type of unintended equilibrium one is trying to avoid, there is a strong case for a more aggressive response to inflation when it is below target. It has been stressed that more aggressive easing reduces the chances of falling into $L T E$ in which policymakers must rely on less familiar instruments with more uncertain effects. ${ }^{48}$ We have shown that responding more aggressively to expected inflation when current inflation is below target makes it possible to avoid BTE.

\footnotetext{
${ }^{47}$ See, for example, Krugman (1998).

${ }^{48}$ See, for example, Orphanides and Wieland (2000).
} 


\section{References}

Benhabib, J., S. Schmitt-Grohe, and M. Uribe (1998) "Monetary Policy and Multiple Equilibria", Finance and Economics Discussion Series 1998-29, Federal Reserve Board.

Benhabib, J., S. Schmitt-Grohe, and M. Uribe (2001a) "Avoiding Liquidity Traps", Journal of Political Economy, 110, 535-563.

Benhabib, J., S. Schmitt-Grohe, and M. Uribe (2001c) "Monetary Policy and Multiple Equilibria", American Economic Review, 91, 167-185.

Benhabib, J., S. Schmitt-Grohe, and M. Uribe (2001b) "The Perils of Taylor Rules", Journal of Economic Theory, 96, 40-69.

Bernanke, B. S., and V. Reinhart (2004) "Monetary Policy at Very Low Nominal Interest Rates", American Economic Review, 94, forthcoming.

Canzoneri, M. B., R. E. Cumby, and B. T. Diba (2001) "Is the Price Level Determined by the Needs of Fiscal Solvency?", American Economic Review, 91, 1221-1238.

Christiano, L. J., and M. Rostagno (2001) "Money Growth Monitoring and the Taylor Rule", NBER Working Paper 8539, National Bureau of Economic Research.

Eggertson, G., and M. Woodford (2003) "The Zero Bound on Interest Rates and Optimal Monetary Policy", Processed, IMF and Princeton University.

Evans, G. W., and S. Honkapohja (2002) "Policy Interaction, Learning and the Fiscal Theory of Prices", Processed, University of Helsinki, (http://ideas.repec.org/ e/pho12.html).

Evans, G. W., and S. Honkapohja (2003) "Policy Interaction, Expectations and the Liquidity Trap", Processed, University of Helsinki, (http://ideas.repec.org/ e/pho12.html).

Krugman, P. (1998) "It's Baack: Japan's Slump and Return of the Liquidity Trap", Brookings Papers on Economic Activity, 2, 137-187.

Leeper, E. (1991) 'Equilibria under 'Active' and 'Passive' Monetary Policies", Journal of Monetary Economics, 27, 129-147.

McCallum, B. T. (2001) "Inflation Targeting and the Liquidity Trap", in N. Loayza and R. Soto (eds.) Inflation Targeting: Design, Performance, Challenges, Central Bank of Chile, Santiago, 395-497 (NBER Working Paper 8225).

Obstfeld, M., and K. Rogoff (1983) "Speculative hyperinflations in maximizing models: Can we rule them out?", Journal of Political Economy, 91, 675-687.

Obstfeld, M., and K. Rogoff (1986) "Ruling Out Divergent Speculative Bubbles", Journal of Monetary Economics, 17, 349-362. 
Obstfeld, M., and K. Rogoff (1996) Foundations of International Macroeconomics, MIT Press, Cambridge.

Orphanides, A., and V. Wieland (2000) "Efficient Monetary Policy Design Near Price Stability", Journal of the Japanese and International Economies, 14, 327-365.

Sargent, T. J. (1987) Macroeconomic Theory, Academic Press, New York, Second Edition.

Schmitt-Grohe, S., and M. Uribe (2000) "Price Level Determinacy and Monetary Policy under a Balanced-Budget Requirement", Journal of Monetary Economics, $45,211-246$.

Svensson, L. E. O. (2000) "The Zero Bound in an Open Economy: A Foolproof Way of Escaping from a Liquidity Trap", NBER Working Paper 7957, National Bureau of Econonmic Research.

Woodford, M. (1994) "Monetary Policy and Price Level Determinacy in a Cash-inAdvance Economy", Economic Theory, 4, 345-380.

Woodford, M. (2001a) "Fiscal Requirements for Price Stability", Journal of Money, Credit and Banking, 33, 669-728.

Woodford, M. (2001b) "The Taylor Rule and Optimal Monetary Policy", processed, Princeton University.

Woodford, M. (2003) Interest and Prices: Foundations of a Theory of Monetary Policy, Princeton University Press, Princeton. 


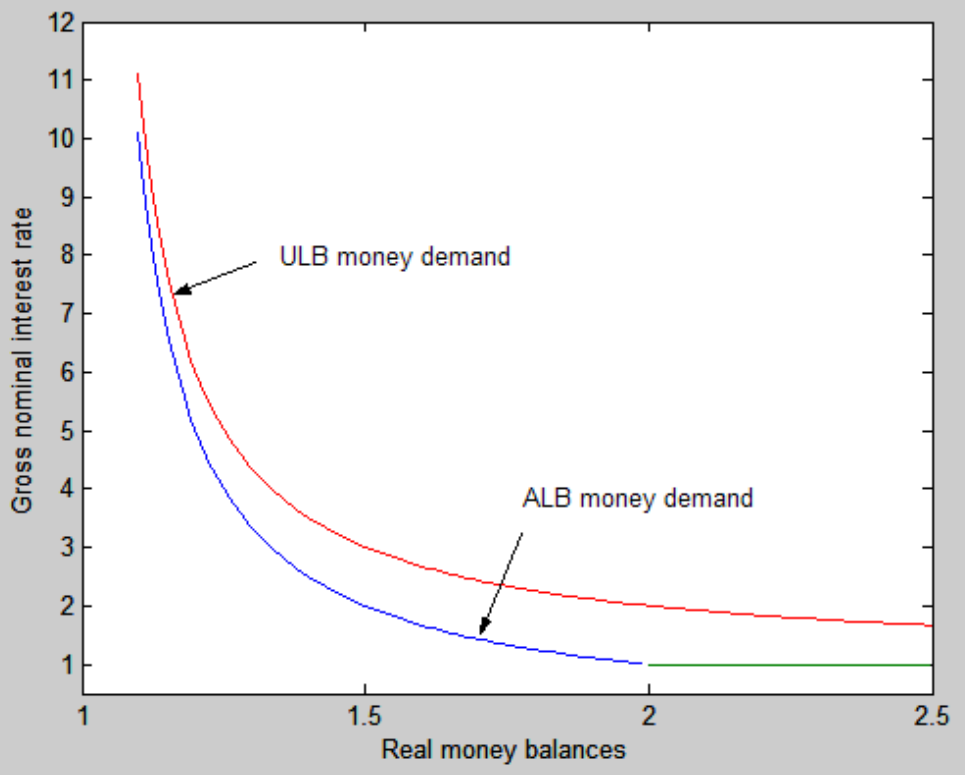

Figure 1: ULB and ALB money demands

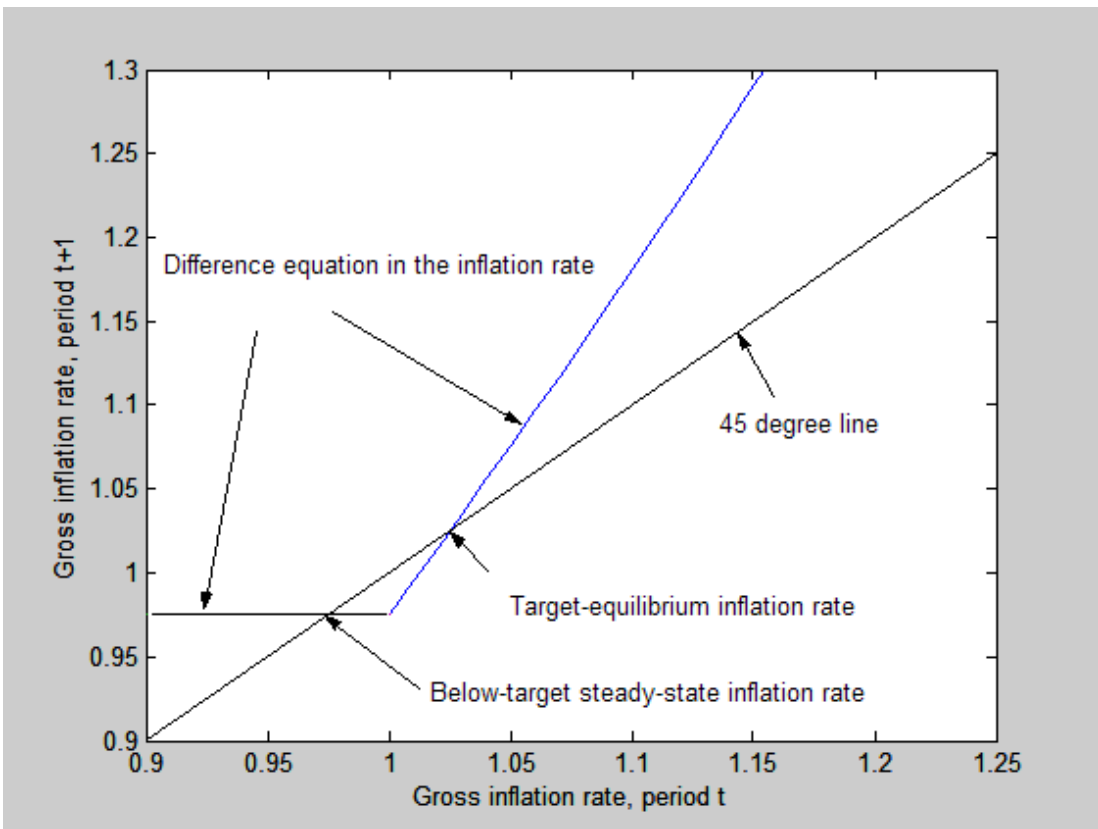

Figure 2: Interest-rate rule and preference-determined lower bound 


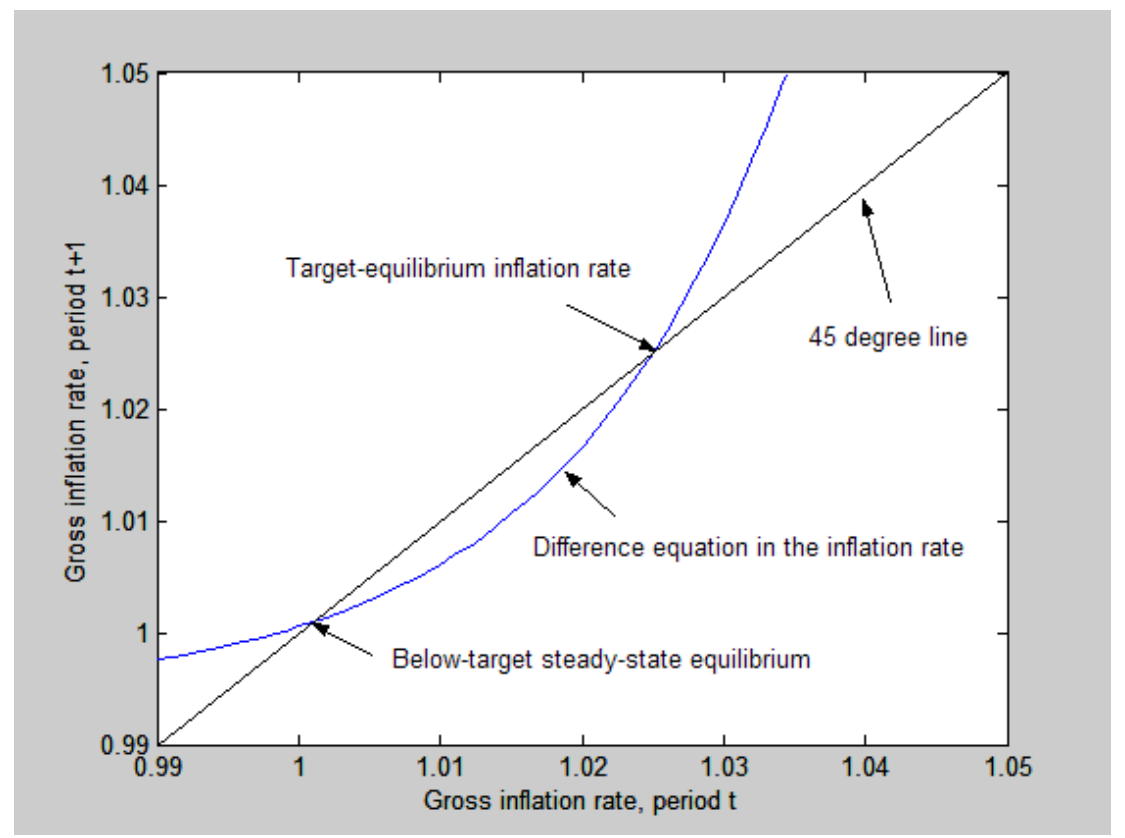

Figure 3: Interest-rate rule and policy-determined lower bound

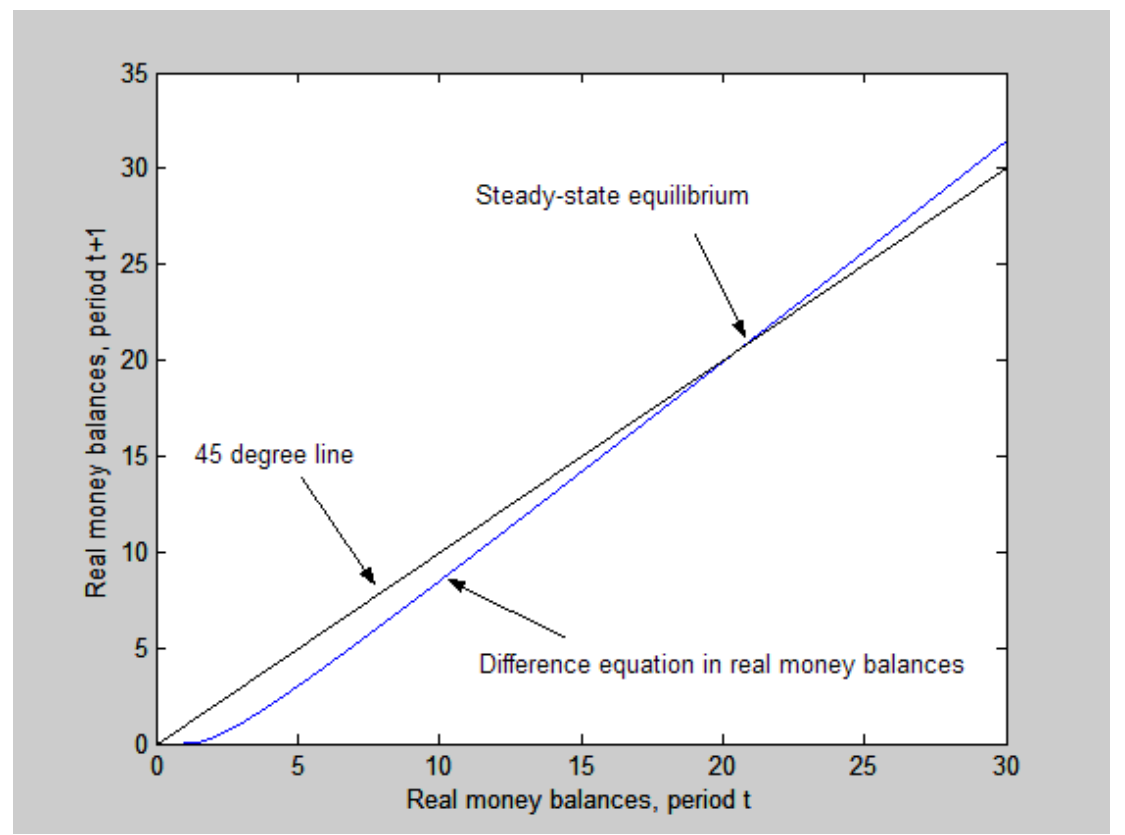

Figure 4: Money-growth rule with unattainable lower bound 


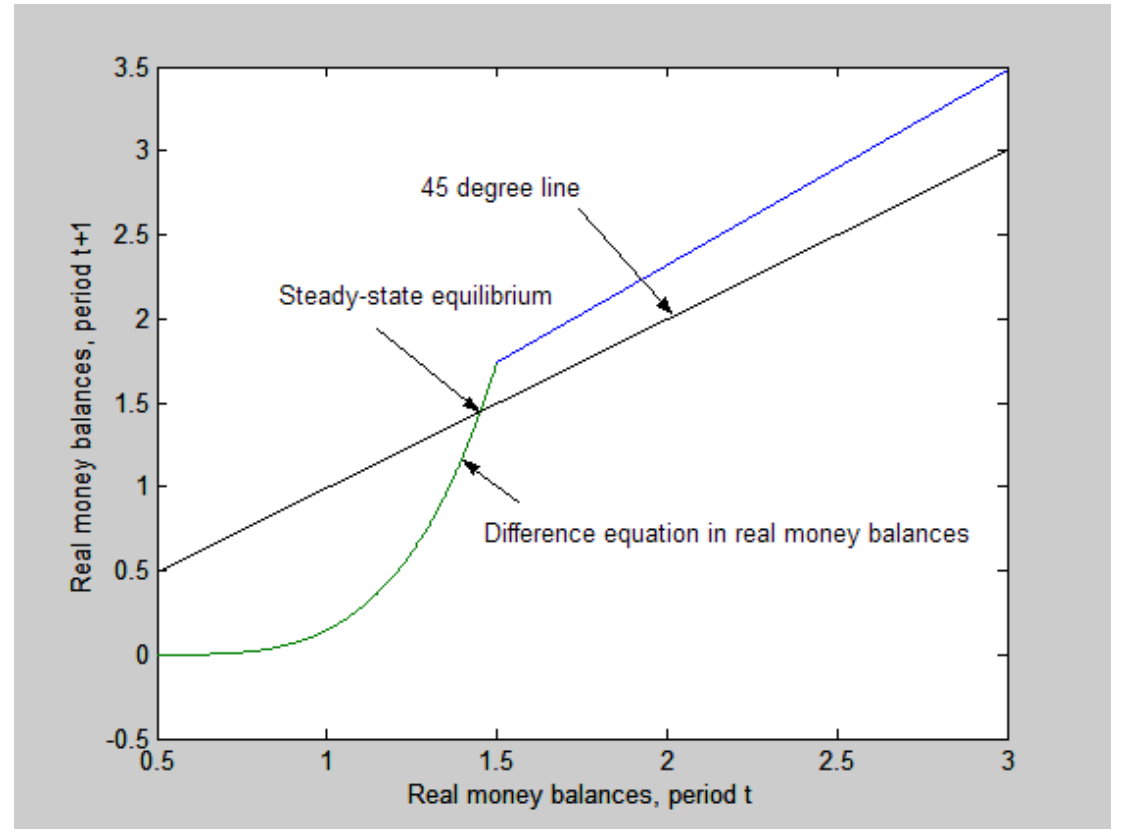

Figure 5: Money-growth rule with attainable lower bound

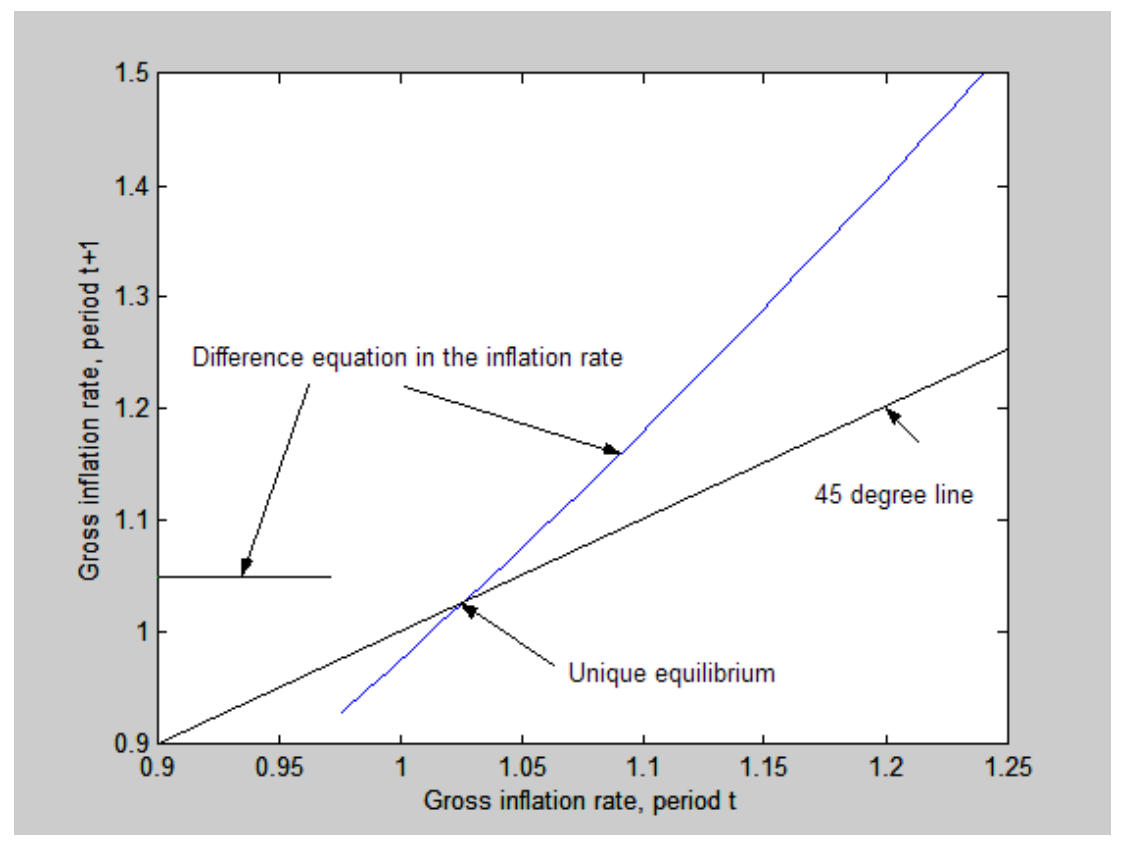

Figure 6: Non-monotonic interest-rate rule 


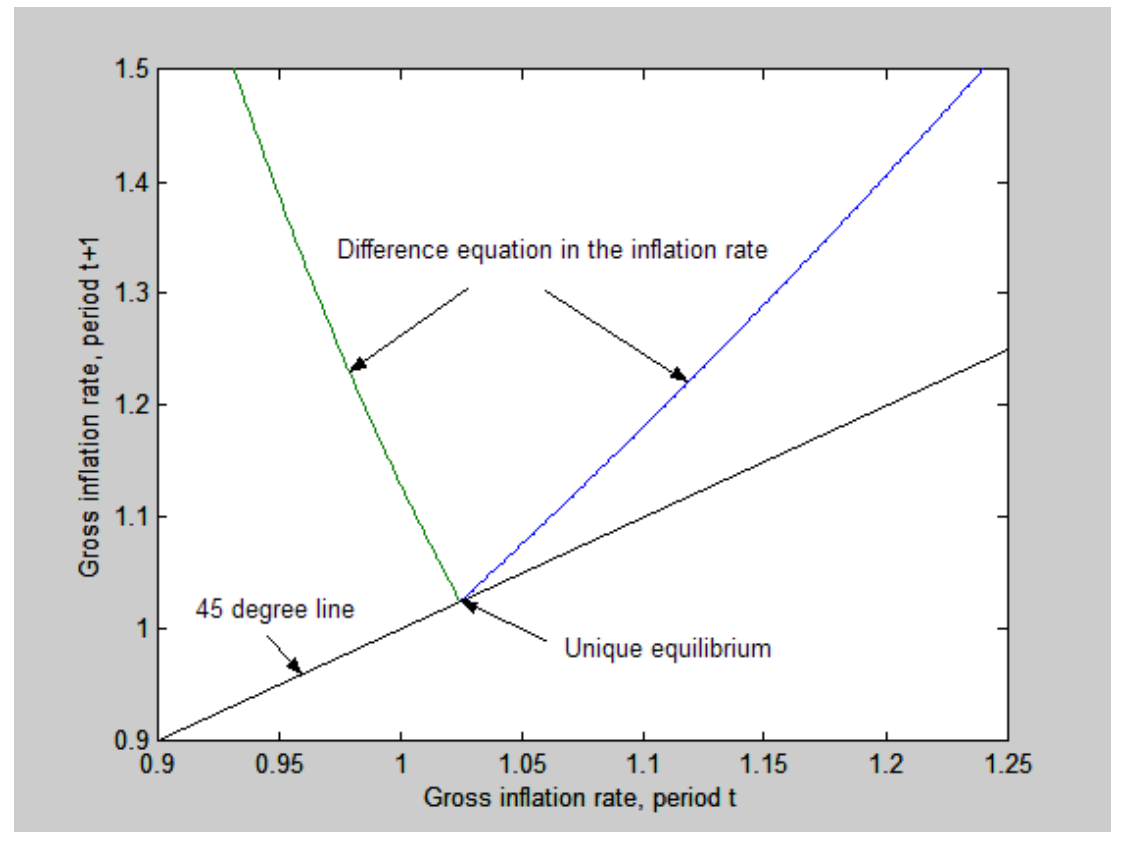

Figure 7: Asymmetric interest-rate rule

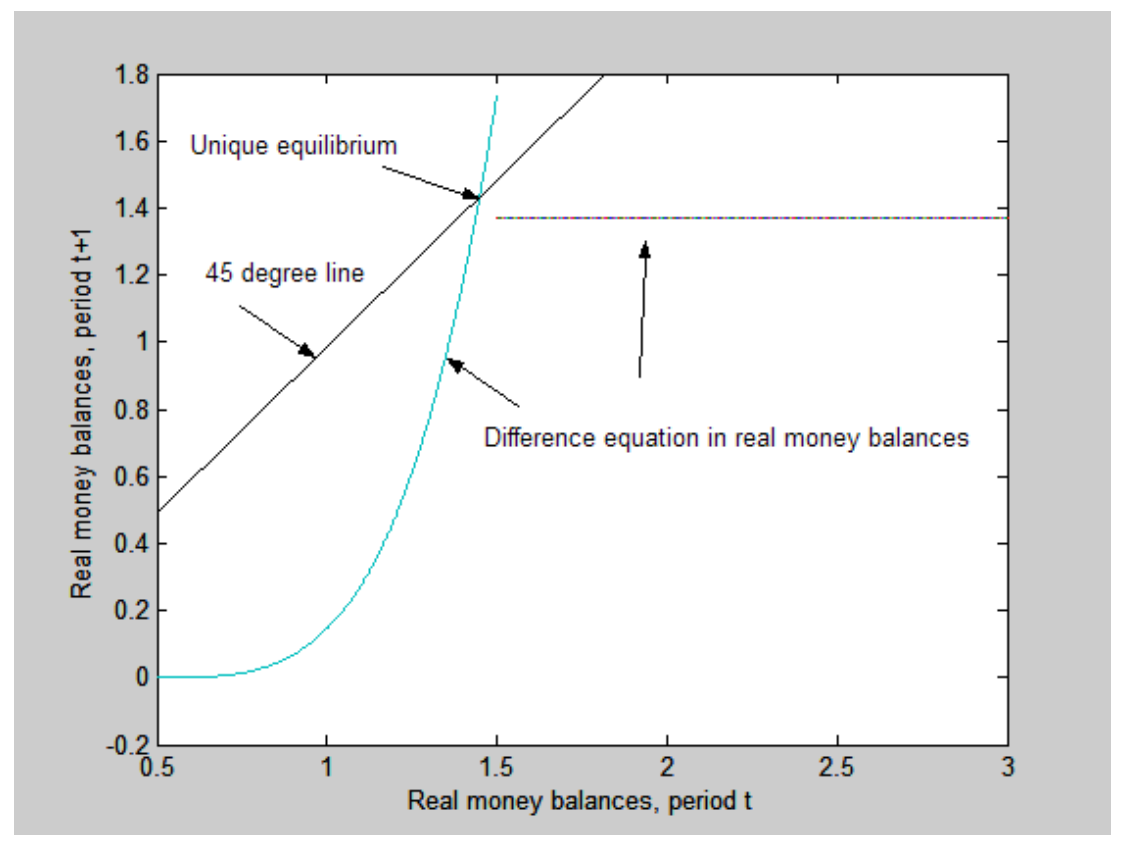

Figure 8: Non-monotonic money-growth rule 